\title{
TRENDS AND PATTERNS IN THE TRIPLE BURDEN OF MALNUTRITION IN INDIA
}

\author{
J.V. Meenakshi \\ Email: meena@econdse.org \\ Department of Economics \\ Delhi School of Economics
}

\section{Working Paper No. 256}

http://www.cdedse.org/working-paper-frameset.htm

\section{CENTRE FOR DEVELOPMENT ECONOMICS}

DELHI SCHOOL OF ECONOMICS 


\title{
Trends and patterns in the triple burden of malnutrition in India
}

\section{J.V. Meenakshi}

\section{Forthcoming in Agricultural Economics}

An earlier version of this paper was presented at a plenary session at the $29^{\text {th }}$ International Conference of Agricultural Economists, 9-14 August 2015

\begin{abstract}
This paper brings together recent evidence on what has come to be referred to as the triple burden of malnutrition - consisting of overnutrition, undernutriton, and micronutrient deficiencies-using various anthropometric, biochemical, and diet quality indicators, and juxtaposing these against changes in relative prices. The evidence points to the rapid emergence of overweight as a public health problem, widespread not only in urban, but also in rural areas; associated non-communicable diseases are also on the rise. Over time, while most indicators of undernutrition have improved, magnitudes are nonetheless high; a persistent problem is anemia, the prevalence of which remains high and unchanged. As for food, more than quantity, it is its quality that appears to be correlated with malnutrition. Yet improvements in diet quality have not been high, and micronutrient intakes remain low. It has become increasingly difficult for the poor to have a diet rich in vegetables, dairy and meat, as their prices (per unit calorie), relative to cereals, have risen faster than for the rich.
\end{abstract}

\section{Keywords}

Nutrition transition, diet quality, malnutrition

\section{Acknowledgements}

I am grateful to Rajarshi Bhowal, Sunaina Dhingra and Deepak Varshney for research assistance and to HarvestPlus for financial assistance. My gratitude also to the referees and to Will Martin who provided detailed comments that have greatly improved this paper. 


\section{Trends and patterns in the triple burden of malnutrition in India}

India continues to be the single largest contributor to the global prevalence of undernutrition. The apparent paradox of the considerable income growth seen in India not leading to commensurate decreases in the prevalence of undernourishment, and similarly of not translating into commensurate reductions in anthropometric measures of undernutrition (stunting, for example) has been the subject of several papers, the most oftcited among them being Deaton and Dreze (2009) and the literature to which it gave rise.

But food and nutrition security is not only about having enough food, but having access to varied sources of food that can help ensure diet quality, so that diets are sufficient not just in calories but also in micronutrients. ${ }^{1}$ Also, malnutrition not only refers to undernutrition (traditionally the focus of countries such as India) it also encompasses overnutrition, and associated non-communicable diseases. The phrase the "triple burden of malnutrition" (see for example Pinstrup-Andersen, 2007) refers to the co-existence of undernutrition, micronutrient deficiencies and overnutrition. Even as India continues to struggle with the burden on undernutrition, problems associated with overnutrition are rapidly emerging as major public health concerns.

Until recently, there were no nationally-representative surveys that collected information on anthropometric (heights, weights) or biochemical (anemia, diabetes) outcomes. ${ }^{2}$ The first National Family Health Survey (NFHS) - the term by which the Demographic and Health Surveys are known in India - was conducted in 1992/93; with subsequent rounds in 1998/99 and 2005/06 (also 2015/16). More recently however, a multiplicity of data sets have become available: for example the District Level Household and Facility Survey (DLHS), the fourth (latest) round of which was in 2012/13, was conducted in most states, while the remaining (poorer states) were canvassed under the Clinical, Anthropometric and Biochemical Survey of 2014 conducted as part of the Annual Health Survey (AHS). In addition, in 2013/14, the Rapid Survey on Children (RSOC) was conducted by UNICEF with a focus only on children. Data from the nationally representative consumer expenditure survey conducted every five years by the National Sample Survey Organization (NSSO) may also be used for information on diet quality and food prices.

Stitching together information from these multiple sources of data, this paper attempts to evaluate trends anthropometric and biochemical indicators of under- and over-nutrition by state, as there is clear evidence of strong regional differences in performance for many outcomes. The paper then juxtaposes these trends with changes in the composition of diets and movements in relative prices. Despite differences in reference populations, age groups, and definitions, the comparisons are illuminating; the caveats-whether for a metric, or across data sources-are detailed in footnotes.

The focus, as the title suggests, is on trends and patterns; this paper does not attempt to provide evidence of causal factors affecting malnutrition. Rather, it attempts to highlight the

\footnotetext{
${ }^{1}$ The World Food Summit of 1996 defined "food security as existing when all people at all times have access to sufficient, safe, nutritious food to maintain a healthy and active life" (italics added). http://www.who.int/trade/glossary/story028/en/ accessed December 28, 2015).

2 The National Nutrition Monitoring Bureau of the Indian Council of Medical Research has conducted regular nutrition surveys since the 1970s, but their samples were restricted to a small number of states and typically focused on rural areas.
} 
new public health challenges thrown up by trends in these data, and to highlight others that seem resistant to change.

State level trends in undernutrition both among children and adult women are the focus of Section 1 while Section 2 does the same with the emerging problems associated with overweight and obesity. Section 3 presents evidence on the relatively modest diet quality transition that has occurred and places it in the context of changes in the relative prices of food. Section 4 presents correlations to characterize the nutrition and diet quality transition at a more disaggregated level to corroborate state-level trends, and Section 5 concludes.

\section{Trends in Undernutrition}

One indicator of undernutrition among young children (under five years) is the prevalence of stunting, which refers to compromised age-specific growth in height and is considered an indicator of long term deprivation. ${ }^{3}$ Another is underweight, which refers to low weights (relative to age), and captures short-term loss in weight due to illness or inadequate food intake. ${ }^{4}$ While both measures pertain to young children, they have long-term economic and health consequences into adulthood, and also for the inter-generational transmission of malnutrition. Undernourished young girls often grow up to be undernourished mothers, who in turn tend to give birth to babies with low birth weights.

Figure $1^{5}$ presents the prevalence of stunting in 1992/93, 2005/06 and 2012-14, for the more populous states, arranged in decreasing order of head count ratios of poverty in 2011/12 (using the official poverty line). ${ }^{6}$ The top panel presents comparisons for the prevalence (among children under five years of age) ${ }^{7}$ of moderate stunting, and the bottom

\footnotetext{
${ }^{3}$ Moderate stunting refers to heights less than 2 standard deviations below the age-specific median height of the reference population; severe stunting is more than 3 standard deviations below the median. Moderate and severe underweight are defined in a similar way.

${ }^{4}$ The reference populations against which heights and weights are compared were drawn from six countries across all continents and represented children from urban elite families (WHO, 2006). In India, the sample was drawn from one city in North India. The reference growth patterns are intended to represent outcomes that can be achieved in the absence of nutritional (whether driven by socio-economic status or disease) constraints. The use of the WHO criteria has been questioned, see, for example, the debates in the Economic and Political Weekly (Panagariya, 2013 and the comments on this paper in the August 23, 2013 issue). Given secular improvements in outcomes, a reference population sampled today would likely yield very different growth charts.

${ }^{5}$ An online data appendix provides the numbers used to construct all the figures presented in the text.

${ }^{6}$ Nearly all the more populous states are included with the exception of Gujarat and Jammu and Kashmir; also excluded are the north-eastern states and union territories which have different consumption patterns.

Further, where possible, unit record data from the NFHS have been used to compute indicators corresponding to current state boundaries.

${ }^{7}$ The 1992/93 data refer to children younger than 48 months, and are thus, strictly speaking, not comparable with figures presented for subsequent years. However, a comparison of the prevalence of stunting (and underweight) for children younger than 48 months with those younger than 60 months, for the year 2005/6 suggests that differences between the two do not exceed more than two percentage points in most states; the assumption in including this year in the comparison is that differences would have been small in 1992/3 as well.
} 
panels do the same for severe stunting. ${ }^{8}$ The data are compiled from multiple sources: the $1992 / 93^{9}$ and $2005 / 06$ data are from the first and third rounds of the National Family Health Surveys (NFHS); those for 2012-14 are from the fourth DLHS (reference year 2012/13) and the Annual Health Survey (AHS) (reference year 2014); while those for reference year 2013/4 are from the RSOC. Although data from the fourth National Family Health Survey for 2015/16 have started to become available, these are still not yet available for all states, and hence are not included in this comparison. ${ }^{10}$

The regional comparisons suggest that while there have been substantial improvements in the level of moderate stunting in most states (Figure $1 \mathrm{~A}$ ), progress has been uneven, with poorer states such Bihar and Uttar Pradesh seeing lower declines than for example Maharashtra and Haryana. Even among the better-off states, there appears to be a leveling off of reductions in the prevalence of stunting: Kerala and Tamil Nadu had the lowest levels of stunting to begin with, but saw hardly any further reduction between 2005/06 and $2012 / 13$ or $2013 / 4$. Furthermore, with few exceptions, there has not been commensurate progress in reducing the degree of severe stunting (Figure 1B); indeed in several states prevalence has remain unchanged between 2005/06 and 2014, after seeing some reduction in the earlier period. Despite overall progress, the magnitude of stunting remains high, with one-fifth to one-third of young children malnourished in most of India's states as recently as two years ago. These trends are broadly similar in rural India. ${ }^{11}$ The caveat about the use of multiple data sources is worth reiterating here: the RSOC data indicate somewhat higher prevalence of moderate stunting in five states, especially among the richer states, and are lower in the rest, but the difference exceeds 10 percentage points in two states.

Figure 2 presents similar comparisons for the prevalence of moderately or severely underweight children. For this indicator, there is an additional year of data from the second round of the District Level Household and Facility Survey. The prevalence of moderate underweight (Figure 2A) has declined in all states. As was the case with stunting, there is some evidence of leveling off of decreases in better off states if the comparison is restricted to 2005/06 and 2012-14 data, but evidence of continued decreases in underweight if the RSOC data for 2013/4 are used. A comparison of the 2013/14 RSOC data with those from

\footnotetext{
${ }^{8} \mathrm{An}$ additional year of data is available from the second round of the National Family Health Survey in $1998 / 99$, but is not included in the figure as the reference age group in that survey was younger (children less than three years).

${ }_{9}^{9}$ Anthropometric measurements were not undertaken in five states during the first round of the NFHS in 1992/93; the graphs therefore present changes only between 2005/06 and 2012-14 for these five states. Also, unit record data have been used to compute the weight-for-age and height-for-age $z$ scores using the WHO (2006) guidelines.

${ }^{10}$ Appendix B presents comparisons between the DHLS4/AHS, RSOC and NFHS4 data sets.

${ }^{11}$ Data not presented for reasons of space. This is consistent with the National Nutrition Monitoring Bureau surveys that show a trend increase in mean heights and weights of young children in rural areas. For example, in rural areas of ten states, mean heights of 4-year old boys increased by $1.4 \mathrm{~cm}$ between 1988-90 to 2011/12 and of 4-year old girls by $1.7 \mathrm{~cm}$ over the same period. Similarly, there was a secular increase in the mean heights of adult men and women (NNMB, 2012)
} 
Figure 1: Trends in prevalence of stunting among young children, by state, 1992/93 to 2012-14

\section{A: Percentage of Young Children Moderately Stunted}

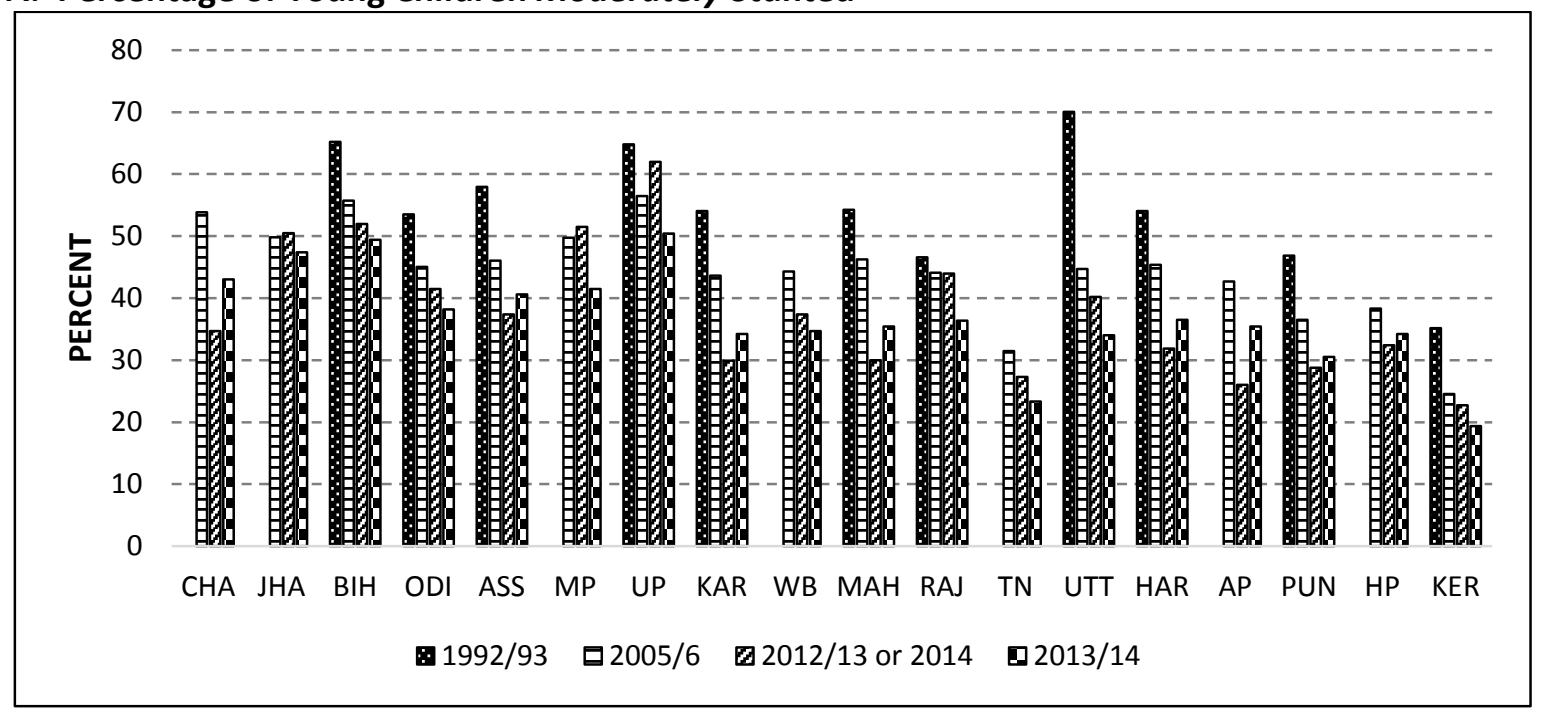

\section{B: Percentage of Young Children Severely Stunted}

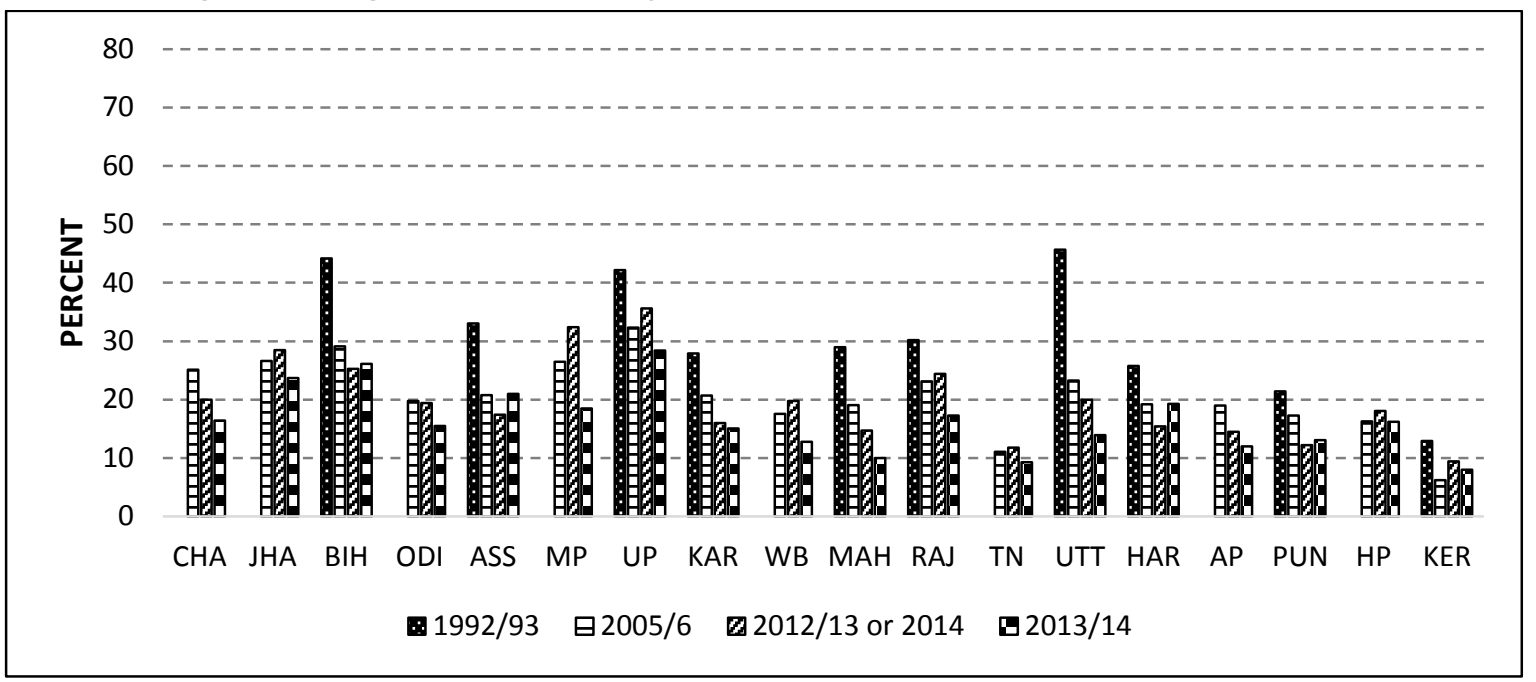

Sources: 1992/93 and 2005/06 data are computed from the unit-record data of the first and third rounds of National Family Health Survey, respectively; this is also the case for some recently-formed states; 2012/13 or 2014 data are from the fourth round of the District Level Household and Facility Survey or the Annual Health Survey; 2013/14 data are from the Rapid Survey on Children.

Notes: 1. See Appendix A for legends of state names; states are arranged in descending order of poverty.

2. 1992/93 data refer to children below 48 months; the other years refer to children below 60 months.

3. Moderately stunted children have HAZ scores below -2 standard deviations from the median of the reference population while severely stunted children have HAZ scores below 3 standard deviations from the median of the reference population. 
Figure 2: Trends in prevalence of underweight among young children, by state $1992 / 93$ to 2012-14 A: Percentage of Young Children Moderately Underweight

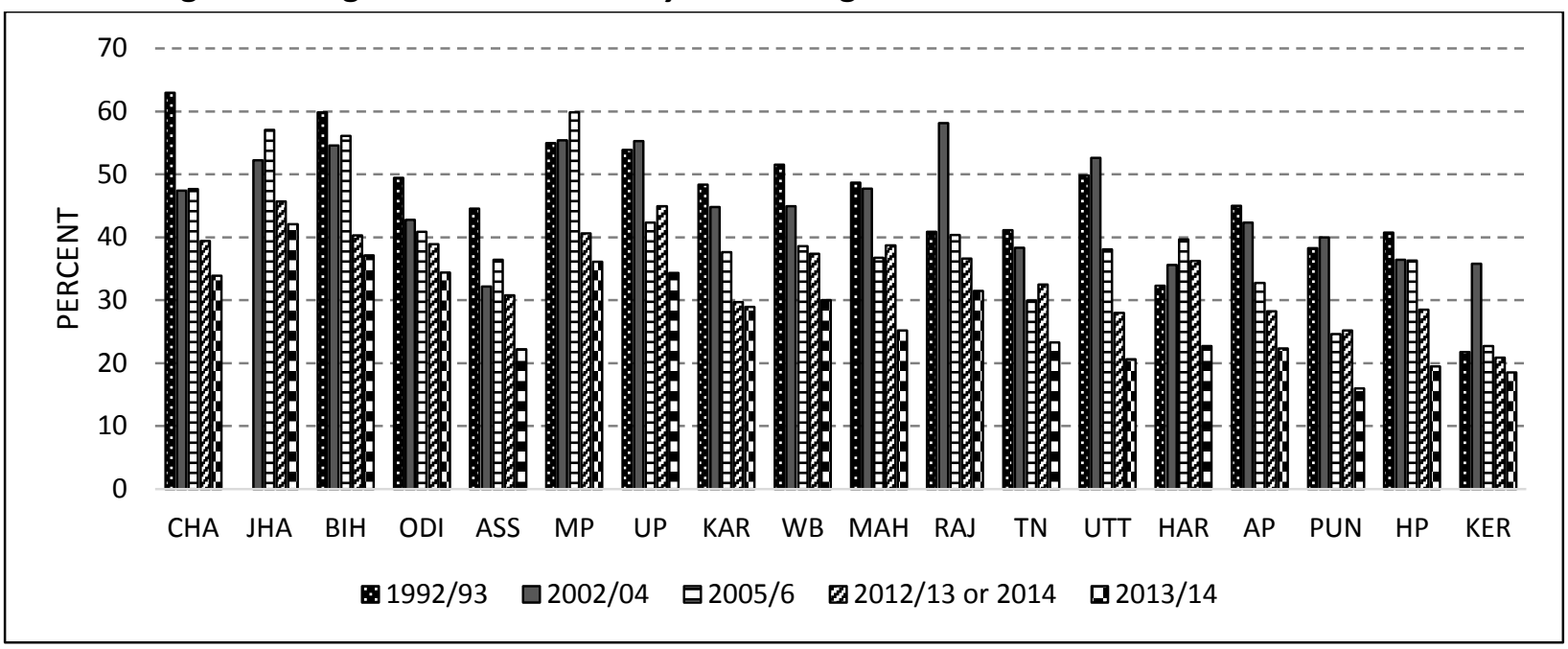

\section{B: Percentage of Young Children Severely Underweight}

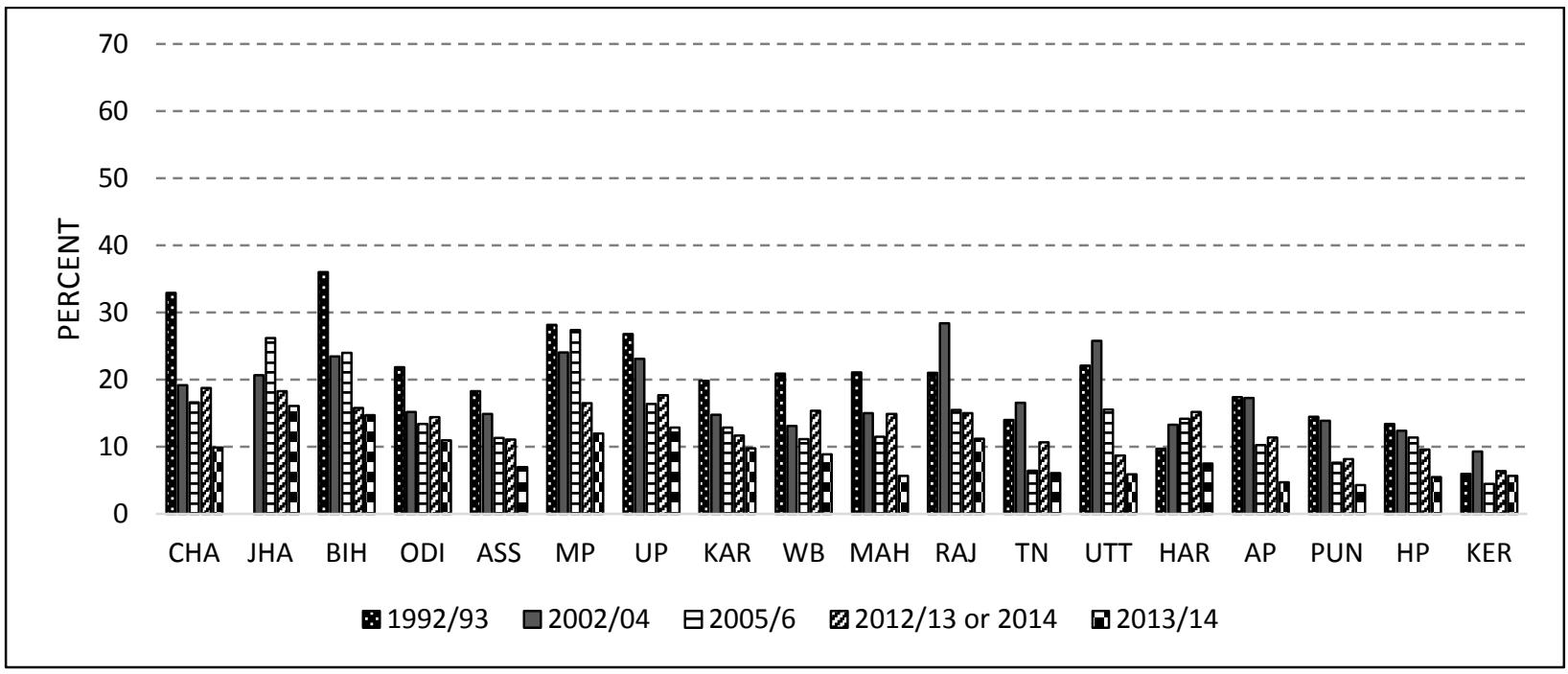

Sources: $1992 / 93$ and 2005/06 data are computed from the unit-record data of the first and third rounds of National Family Health Survey, respectively; this is also the case for some recently-formed states; 2002/04 data are from the second round of the District Level Household and Facility Survey; 2012/13 or 2014 data are from the fourth round of the District Level Household and Facility Survey or the Annual Health Survey; 2013/14 data are from the Rapid Survey on Children.

Notes: 1. See Appendix A for legends of state names; states are arranged in descending order of poverty.

2. 1992/93 data refer to children below 48 months; $2002 / 04$ data refer to children below 72 months; the other years refer to children below 60 months.

3. Moderately underweight children have WAZ scores below -2 standard deviations from the median of the reference population while severely underweight children have WAZ scores below -3 standard deviations from the median of the reference population. 
the DLHS/AHS for 2012-14 in the graph shows that the RSOC figures are generally lower, usually by 6-7 percentage points or less, but the differences are particularly large for some states and exceed 10 percentage points for Haryana, Maharashtra and Uttar Pradesh; it is unlikely that such large reductions were achieved within a span of one or two years.

An important manifestation of undernutrition among adults is anemia, which results both from inadequate dietary intakes of iron, as well as exposure to certain types of infection. Being anemic results in diminished work capacity and lower earning potential; among pregnant women, it can also lead to adverse pregnancy outcomes (see references cited in Stein et al., 2008). In 2012/13, the prevalence of any anemia among adult women ranged from one-third in Kerala to a high of three-fourths in West Bengal, with relatively small rural-urban differences. Of greater concern is the fact that over time ${ }^{12}$ anemia has not only not declined, rather, it seems to have increased, as demonstrated in Figure 3. If anything, the increases depicted are understated for some of the states as the 2012/13 data from the DLHS use a somewhat lower cut-off (11 grams per deciliter) than the AHS surveys (which use 12 grams per deciliter) to determine anemia. ${ }^{13}$ It is important to note however that this may in part be due to differences in methods used in blood-sample analysis; for as noted in Appendix B, anemia prevalence reported by NFHS 4 is far lower than by the DLHS 4/AHS. An example of a large difference across data sources is provided by Madhya Pradesh, with 83.7 percent anemia according to DLHS 4/AHS but 52.5 percent according to NFHS 4; such implausibly large differences across the two to three years that separate the DLHS/AHS and NFHS surveys are not uncommon. Comparison across the two NFHS surveys in 2005/06 (in Figure 3) and 2015/16 (in Appendix B) for the limited number of states where this comparison is possible suggests a reduction in anemia of between 5 and 8 percentage points in five states, and show an increase in and Haryana, and virtually unchanged anemia prevalence in Tamil Nadu, West Bengal and Maharashtra.

Although adverse functional and health consequences are associated with moderate and severe anemia, it is clear that anemia is a widespread public health problem, and one that is not limited to adult women, but extends to adolescents and children as well. Further, even richer states such as Haryana, which have lower prevalence rates than poorer states, have seen increases in anemia over time. As noted later, the lack of improvement in anemia prevalence is consistent with decreases in intakes of iron; but these high magnitudes have not seen the kind of policy response that is clearly warranted.

Another indicator of poor nutritional outcomes is the percentage of women who have a body mass index (BMI)-defined as weight in kilograms divided by the square of height in meters--of less than 18.5. Such women are thin, and is generally indicative of inadequate food intake. Over time this percentage has clearly decreased in all states (Figure 4A), with much of the decline occurring in the last decade: in the late 1990s, 12 out of the 16 states considered had over one-third of women being thin; the most recent figures suggest that no state had more than 30 percent. The decreases were more rapid in the poorer states in

\footnotetext{
12 Data for 1998/9 and 2005/6 refer to ever-married women aged 15-49 years; those for 2012/13 refer to adult women aged 15-49 years, while 2014 data refer to women aged 18-59 years.

${ }^{13}$ Anemia is also categorized by degree of severity; hemoglobin levels under 10 grams per deciliter are indicative of moderate anemia; under 7 grams per deciliter, of severe anemia.
} 
Figure 3: Trends in prevalence of anemia among women, by state, $1998 / 99$ to 2012-14

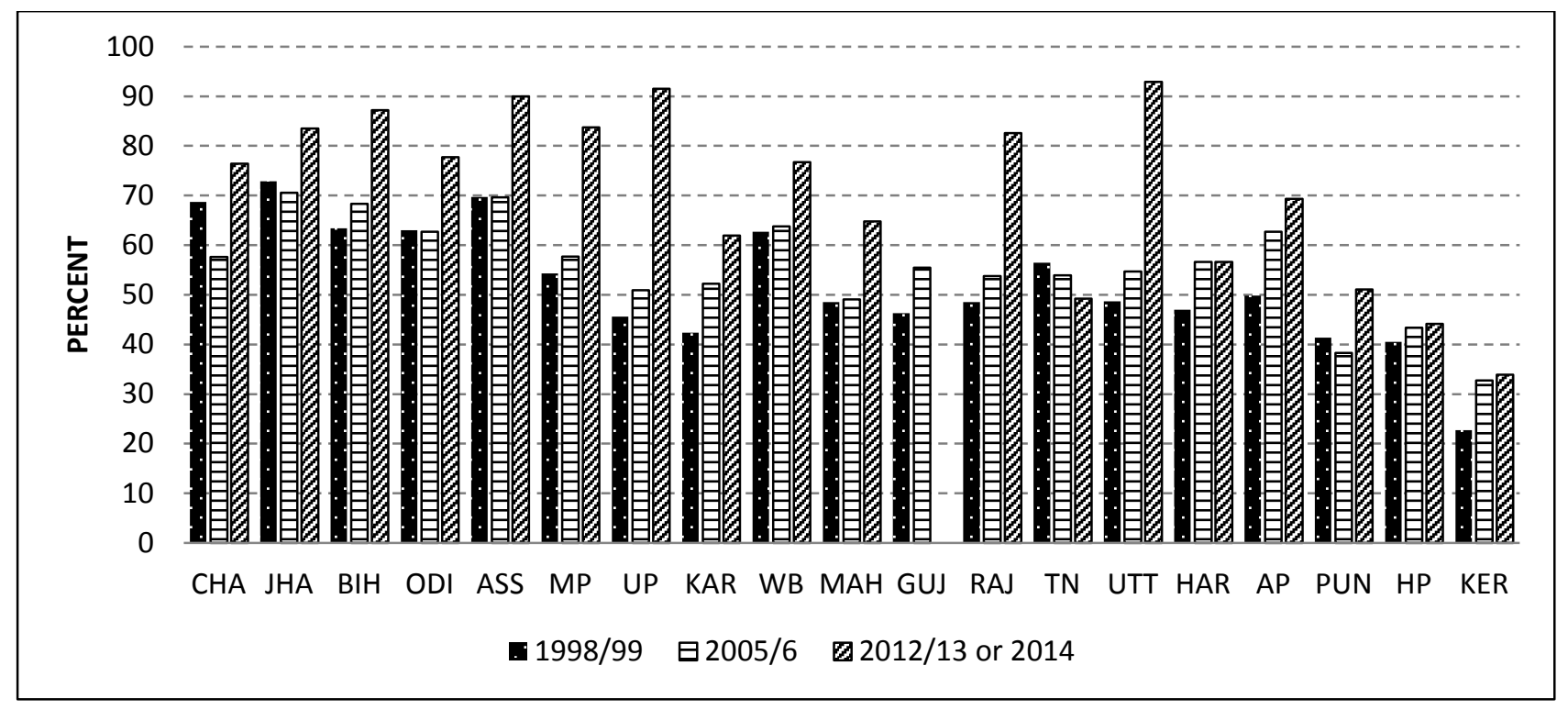

Sources: 1998/99 and 2005/06 data are computed from the unit-record data of the second and third rounds of the National Family Health Survey; 2012/13 or 2014 data are from the fourth round of the District Level Household and Facility Survey or the Annual Health Survey. See text for additional details.

Notes: 1. See Appendix A for legends of state names; states are arranged in descending order of poverty.

2. 1998/99 and 2005/06 data refer to women aged 15 to 49 years and use a cut-off of $12 \mathrm{~g} / \mathrm{dl}$ to determine anemia status. 2012/13 data refer to women aged 15 to 50 years and use a cutoff of $11 \mathrm{~g} / \mathrm{dl}$ to determine anemia status; while 2014 data refer to women aged 18 to 59 years and use a cut-off of $12 \mathrm{~g} / \mathrm{dl}$.

Eastern India: for example, Bihar saw a near-halving of the percentage of undernourished women. These patterns are largely driven by trends in rural India, as shown in Figure 4B.

\section{Trends in overnutrition}

Over the same period, there has been an increase in overnutrition, as measured by the percentage of women with a BMI of over 25 who are either overweight (BMI more than 25) or obese (BMI more than 30 ). This is demonstrated in Figure $5 \mathrm{~A}$, which indicates an increase in nearly all states, even though the magnitudes remain below 15 percent in the poorer states. These increases have occurred fairly rapidly, in 1998/9 only two states had overweight prevalence exceeding 20 percent; that number has gone up to six in 2012-14. In fact, in some states, notably in southern India (especially in Tamil Nadu and Kerala) and in richer states (Punjab, Himachal Pradesh), the percentage of women who are overweight is greater than those who are thin.

While the emergence of overnutrition as a public health concern in India has been recognized for some years (see for example Vaz et al., 2005; Ramachandran 2014; 2006), it 
Figure 4: Percentage of women who are thin (BMI <18.5), by state and residence, $1998 / 99$ to 2012-14

\section{A: Percentage of Women with BMI $<18.5$, Total}

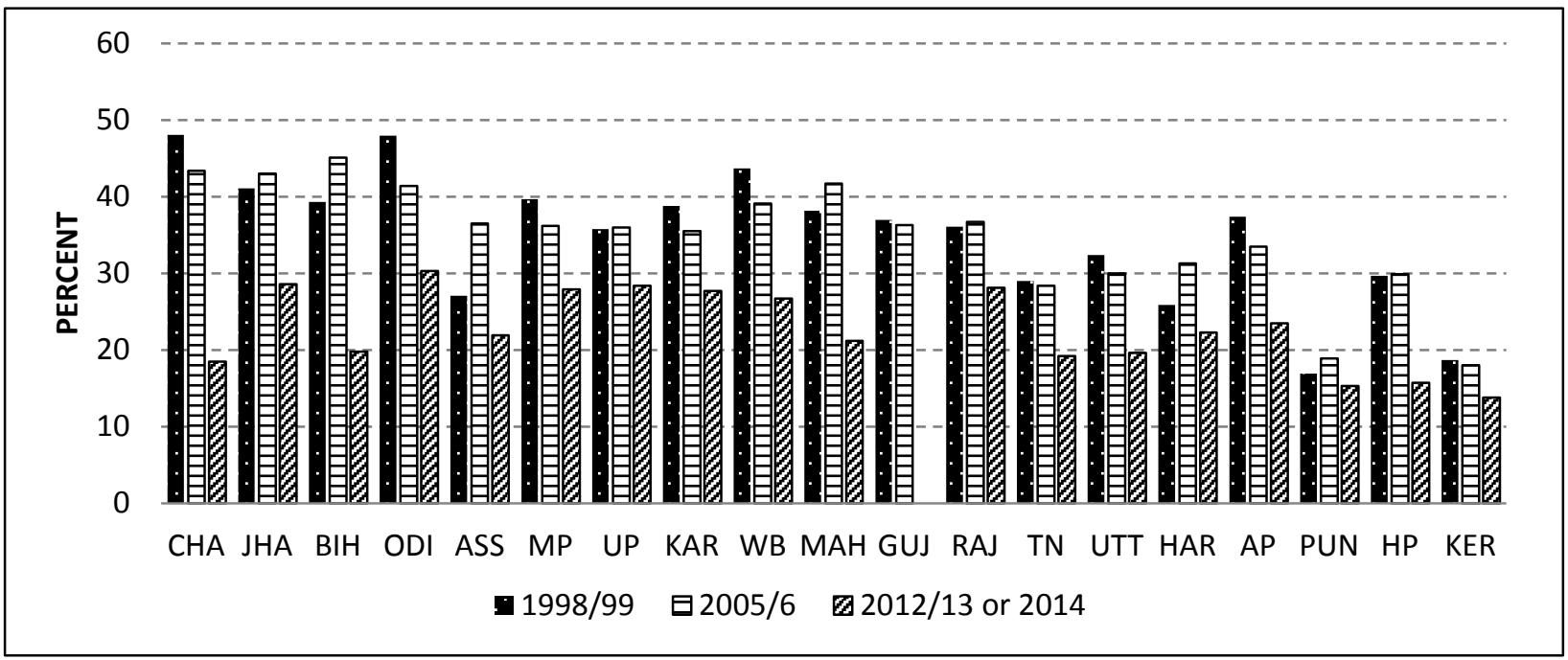

\section{B: Percentage of Women with BMI $<18.5$, Rural}

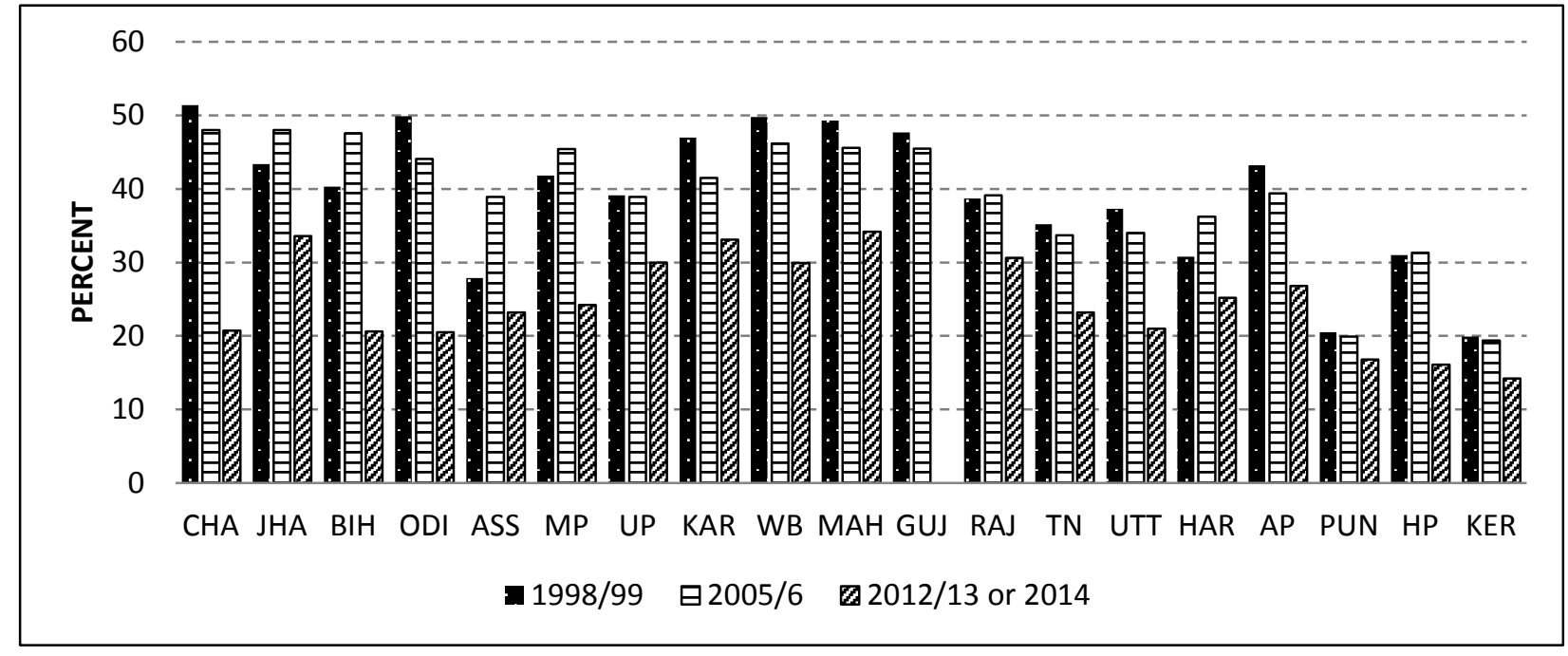

Sources: 1998/99 and 2005/06 data are computed from the unit-record data of the second and third rounds of the National Family Health Survey; 2012/13 or 2014 data are from the fourth round of the District Level Household and Facility Survey or the Annual Health Survey. See text for additional details.

Notes: 1. See Appendix A for legends of state names; states are arranged in descending order of poverty.

2. $1998 / 99$ and $2005 / 06$ data refer to women aged 15 to 49 years; $2012 / 13$ data refer to women aged 15 to 50 years; and 2014 data refer to women aged 18 to 59 years. 
Figure 5: Percentage of women who are overweight or obese (BMI > 25), by state and residence, 1998/99 to 2012-14

\section{A: Percentage of Women with BMI $>25$, Total}

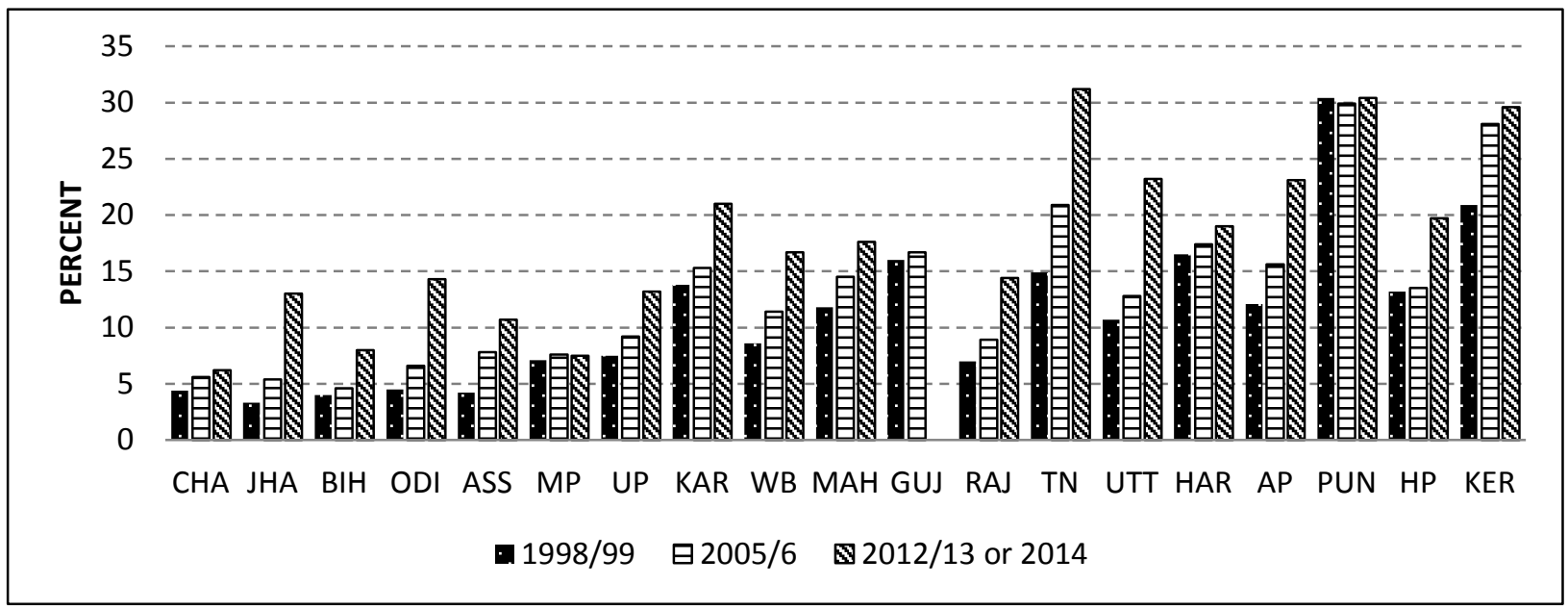

B: Percentage of women with BMI $>25$, Rural

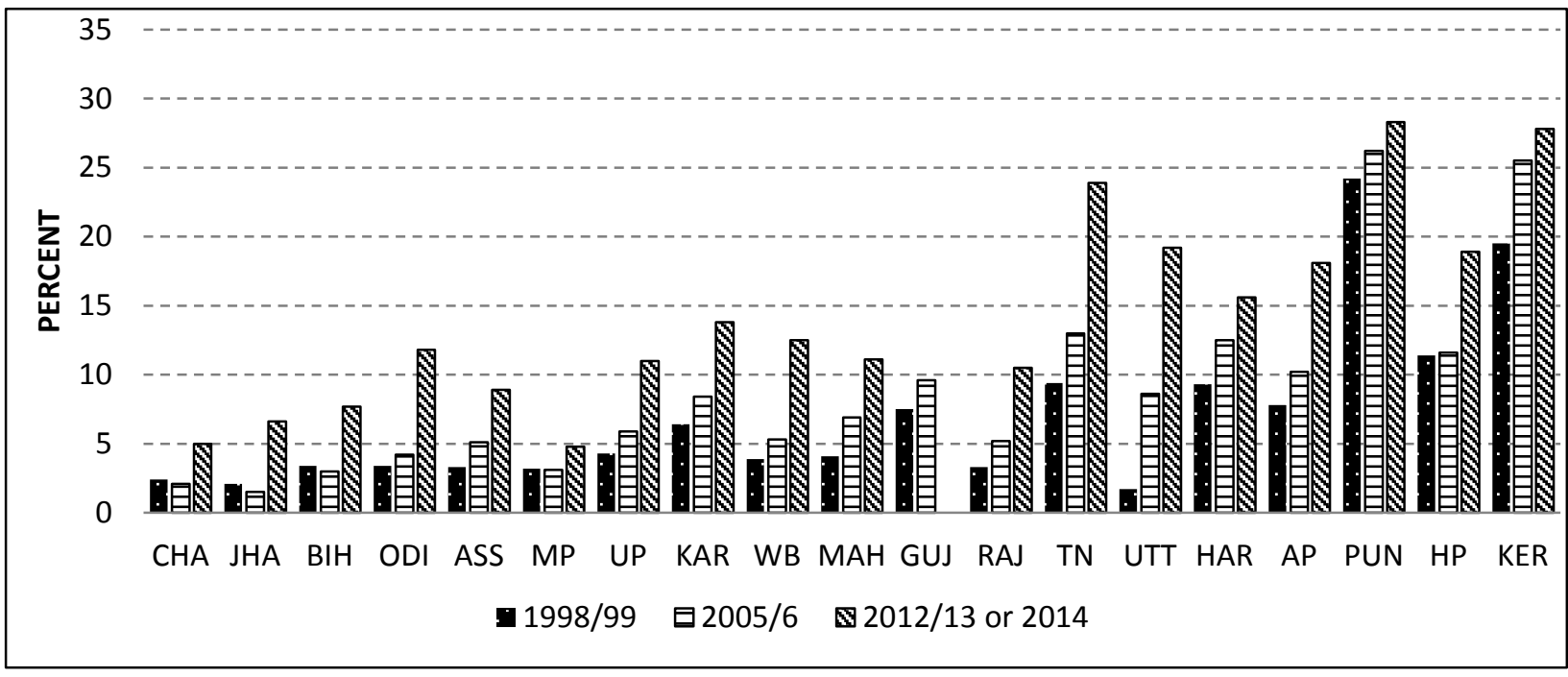

Sources: 1998/99 and 2005/06 data are computed from the unit-record data of the second and third rounds of the National Family Health Survey; 2012/13 or 2014 data are from the fourth round of the District Level Household and Facility Survey or the Annual Health Survey. See text for additional details.

Notes: 1. See Appendix A for legends of state names; states are arranged in descending order of poverty.

2. $1998 / 99$ and $2005 / 06$ data refer to women aged 15 to 49 years; $2012 / 13$ data refer to women aged 15 to 50 years; and 2014 data refer to women aged 18 to 59 years. 
has typically been thought that overnutrition is largely associated with urbanization (in part because of the more sedentary nature of lifestyles in urban areas, and higher incomes), and that undernutrition remains a greater problem in rural areas (FAO, 2006). For instance, Kulkarni et al. (2014), based on a different data source, found that "overweight and obese women were largely concentrated in affluent households." The more recent evidence presented above clearly challenges a part of this received wisdom: while it is true that overnutrition is associated with higher levels of income, it is no longer just an urban problem: the magnitude of overweight and obese women in rural areas now far exceeds the percentage of thin women in the rural areas of the four states mentioned above (Figure 5B). Furthermore, overnutrition is increasing rapidly: in 10 of 16 states the rural prevalence of overnutrition exceeds $15 \%$. The increases are not uniform across states: with southern states recording much greater increases in obesity. Regional specificities in nutritional outcomes are reported by other studies as well, including Ackerson et al. (2008). Although these magnitudes are still far lower than those found in more developed countries such as the United States (where two-thirds of adults were overweight or obese), ${ }^{14}$ Indians appear to be catching up quickly.

The recent DLHS and AHS surveys also canvassed data on blood sugar readings (magnitudes greater than $140 \mathrm{mg} / \mathrm{dl}$ being indicative of diabetes) as well as metrics on hypertension. For these indicators a comparison over time is not possible, but it is clear that chronic diseases associated with problems of overnutrition are approaching magnitudes that constitute a public health problem. And as was the case with overweight and obesity, this is no longer an urban problem, with 7 to 15 percent of rural populations in better-off states reporting random blood sugar readings in excess of 140 . Similarly, in many states, nearly a quarter of adults have hypertension. These magnitudes are comparable to those found among adults in the United States, for example, which has far higher levels of overweight and obesity.

A more disaggregated analysis, using data for a single cross section (2012/13 or 2014) for districts (which are administrative sub-divisions of states) suggests there is an inverse relationship between the extent of undernutrition and of overnutrition. For instance, as indicated in Figure 6, across districts, there is the predicted negative relationship between overweight/obesity and thinness, but the correlation is low at -0.3. There are some exceptions to this pattern: many districts, notably in Tamil Nadu, have high levels of both under- and over-nutrition, but this is generally not the case in most other states. Were populations in most districts within 'normal' ranges of weights, most of the districts would cluster in the lower left region of the graph. However, there is a great deal of variability at especially at low levels of thinness. A similar pattern obtains with other indicators of undernutrition such as anemia and stunting (figures not presented here for reasons of space). ${ }^{15}$

\footnotetext{
${ }^{14}$ See http://www.cdc.gov/nchs/fastats/obesity-overweight.htm, accessed December 31, 2015

${ }^{15}$ There are also concerns about the intra-household distribution of food and nutrients. For example, in rural India, it is not uncommon to find households where the adults are adequately nourished but the children are not (Ramachandran, 2006). In rural India, for example, in 2005/6, one percent of households had children with an overweight mother and an underweight child; a double burden within the household. Another 23 percent of households had the expected underweight children with mothers with BMI less than 18.5; while 21 percent of households had women with normal BMI but underweight children. Thus, at least in 2005/6 there was no double burden of malnutrition, although clearly intra-household distribution issues were important. But this
} 
Figure 6: Association (district-level) between percentage of women who are thin and overweight/obese, 2012-14

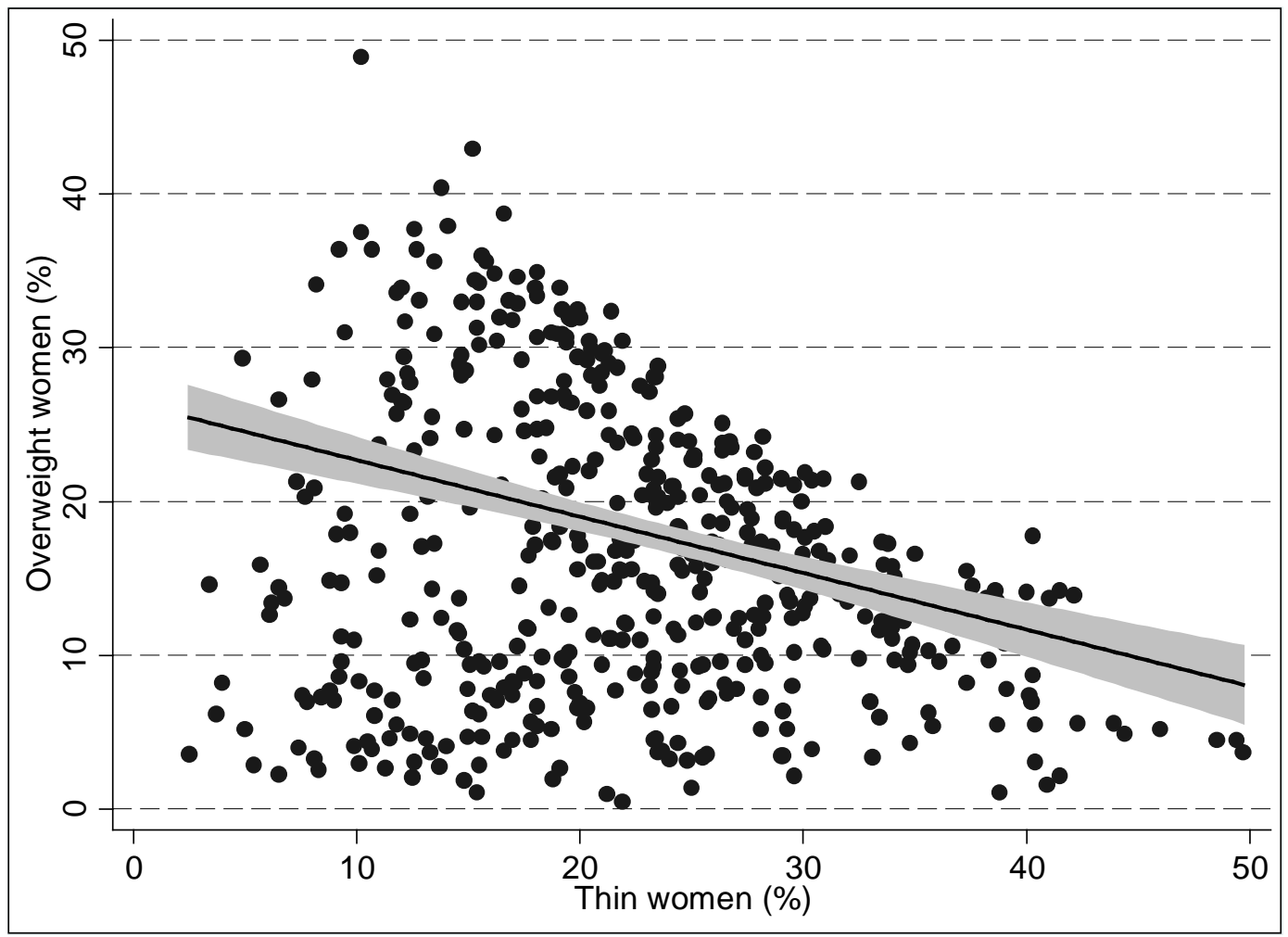

Sources: 2012/13 or 2014 data are from the fourth round of the District Level Household and Facility Survey or the Annual Health Survey. See text for additional details.

\section{Changes in Diet Quality and Relative Prices}

To what extent might these trends be explained by changes in diets and diet quality? Traditionally, the focus of food security has been on energy intake, which appears to have steadily declined over time, and to exhibit extremely small income elasticities of demand (Deaton and Dreze, 2009). ${ }^{16} \mathrm{~A}$ similarly low elasticity appears to characterize the relationship between nutritional outcomes and food intake. Figure 7A compares the change in stunting among young children on the vertical axis between 1992/93 and 2012-14, with those in average energy intake, expressed as calories per capita per day (pcpd) on the horizontal axis. The latter data are computed from the consumer expenditure surveys of the National Sample Survey Organization (NSSO) for the survey years 1993/94 (50 ${ }^{\text {th }}$ round of the NSSO) and 2011/12 (68 ${ }^{\text {th }}$ round of the NSSO), which correspond roughly to the time period used for tracking anthropometric indicators.

was also a time when the prevalence of owomen with $\mathrm{BMI}>25$ was relatively small; it remains to be seen if this pattern has changed more recently. See also Ramachandran (2011).

${ }^{16}$ There is a rich literature (for example, Eli and Li, 2015; Atkin, 2013; Basole and Basu, 2015) that offers explanations for this paradox, but a review of this is beyond the scope of this paper. 
Figure 7: Changes in prevalence of stunting and quantity and quality of food intakes, by states, early 1990s to early 2010s

\section{A: Prevalence of Stunting and Caloric Intakes}

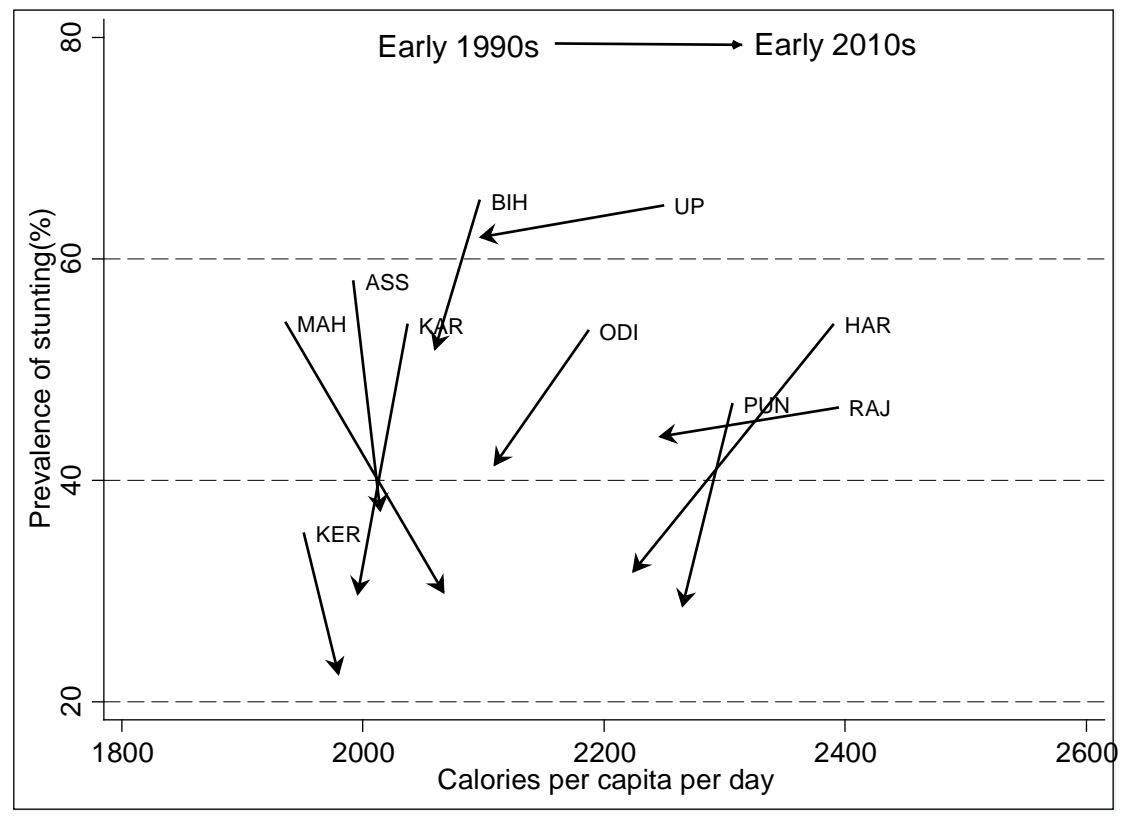

\section{B: Prevalence of Stunting and Share of Calories from Non-Staples}

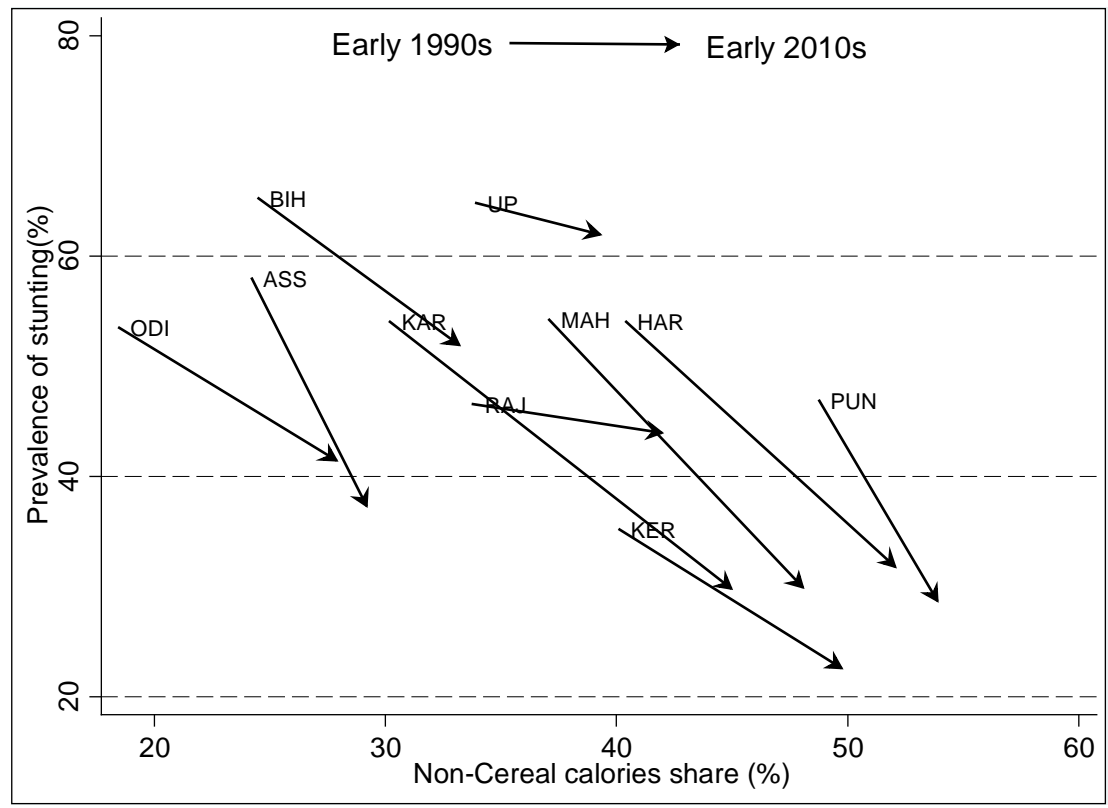

Sources: Stunting data are from the first round of the NFHS (1992/93) and fourth round of District Level Household and Facility Survey and Annual Health Survey (2012-14); calorie and calorie share data are from the $50^{\text {th }}$ and $68^{\text {th }}$ rounds of the National Sample Survey Organization surveys.

Notes: 1 . See Appendix A for legends of state names.

2. Early 1990 s refers to $1992 / 93$ for stunting and $1993 / 94$ for calories and calorie shares; early 2010s refers to 2012-14 for stunting and 2011/12 for calories and calorie shares. 
If energy intakes were strong predictors of child nutritional outcomes then the arrows in the graph would be expected to slope downward and to the right. But this is not the case: in fact there is no systematic relationship-stunting fell in all states, while per capita calorie consumption sometimes rose and sometimes fell. In part the lack of a pattern may be attributed to the apparent decline in energy intake over time; some of this decline, as detailed below, may well be due to measurement error that is varying over time. ${ }^{17}$

Figure 7B compares changes in anthropometric outcomes with those in diet quality as measured by the share of energy derived from non-cereals. This measure is based on what has come to be called Bennett's law, which suggests that with economic development diets become more diversified and less reliant on staples. In particular, Bennett noted that "ratios of cereal-potato calories to total food calories may be regarded as an indicator of relative qualitative adequacy of national diets" (Bennett, 1941). Although there is no direct trade-off between quality and quantity of food in the diet, and caloric deficits cannot be compensated for by improved quality, there is evidence to suggest that dietary adequacy in the sense of the quote from Bennett above, and anthropometric outcomes, are correlated.

To get a more nuanced picture of diet quality, Figure 8 provides trends in the shares of budgets, energy, and iron intakes accounted for by various food groups. These include cereals (higher shares being indicative of poorer diet quality), pulses (rich in protein), meat, eggs and fish; and fruits and vegetables (where higher shares are associated with better diet quality and therefore expected to help in ameliorating undernutrition), and in oils and sugars (with higher shares being indicative of worsening diet quality, and contributing perhaps to worsening overnutrition). These are computed using the consumer expenditure surveys of the NSSO, where the unit of observation is the household, and disaggregated by tercile expenditure group to help assess if the pattern (and not just the level) of diet diversification varies substantially by income group. A regional disaggregation is not presented for the salient trends are similar, but is available on request.

At first glance, trends in budget shares are indicative of a substantive change in diet quality across all expenditure terciles (Figure 8A). Food budget shares have declined: for example from over $75 \%$ in $1993 / 94$ to about $60 \%$ in $2011 / 12$ for the poorest tercile; accounted for entirely by reduced expenditure shares of cereals. There have been modest increases in shares of meat, eggs and fish among the poorer terciles, and also in the share of other foods. The shares devoted to oils and sugars and fruits and vegetables have remained relatively unchanged across expenditure groups. By 2011/12, the middle income tercile devoted nearly identical shares of their budget to cereals and meat, eggs and fish of approximately 13 percent, followed by fruits and vegetables, which accounted for 8 percent. The dominance of cereals in budget shares is decreasing: even among the poorest tercile, cereals accounted for less than $20 \%$ of all expenditures.

\footnotetext{
${ }_{17}$ Measurement error aside, it is important to note that the decrease in mean energy intakes between 1993/94 and 2011/12, has not meant that the entire distribution of energy intake has shifted left; rather the left tail of the distribution has shifted right, so that, for example, the percentage of people whose caloric intake lies below 1800 calories per capita per day is lower in 2011/12 than in 1993/94; there is also a greater mass in the density just below the mean. In other words, the cumulative distribution functions cross. This, along with a secular decrease in activity levels, and diet diversification, helps explain why it is not inconsistent for the magnitude of undernutrition (women with $\mathrm{BMI}<18.5$ or underweight children) to have declined despite a decrease in mean energy intakes.
} 
Figure 8: Changes in shares of foodgroups in budgets, calories, and iron, by tercile expenditure group, $1993 / 94$ to $2011 / 12$

\section{A: Total Budget shares}

\section{Total Budget Share}

100

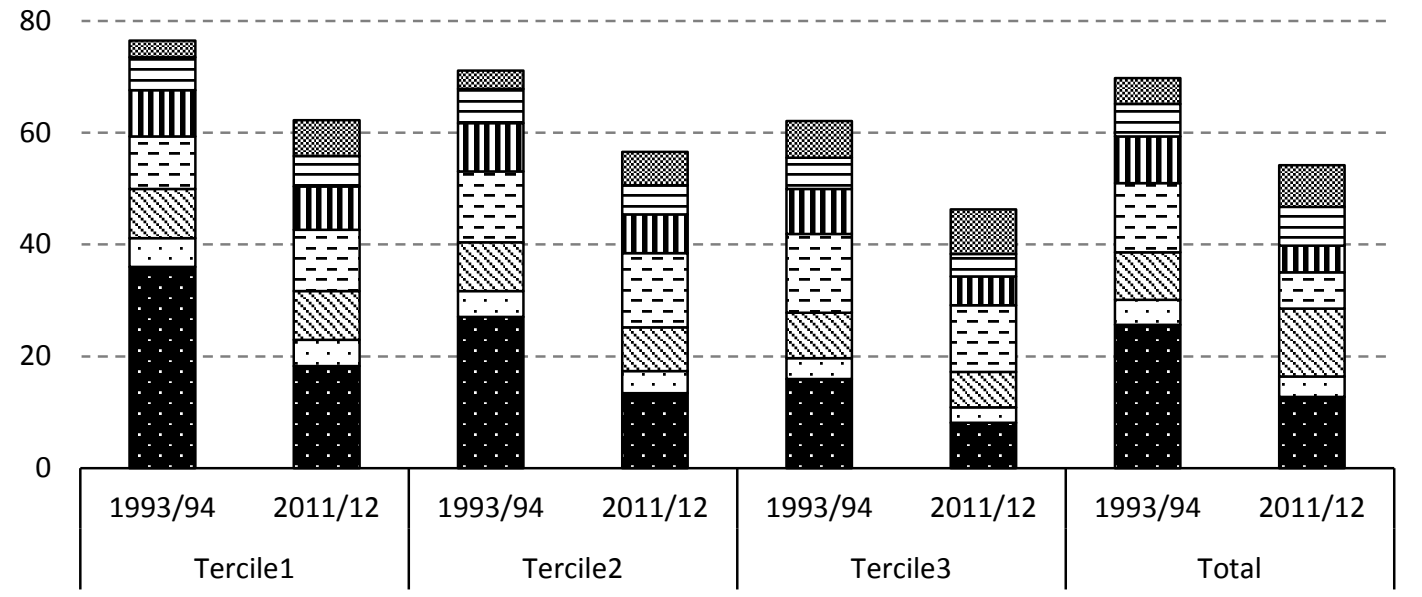

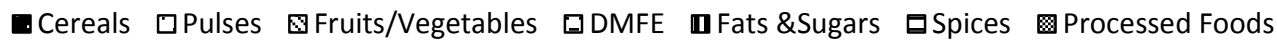

B: Intake of Calories (cal/capita/day)

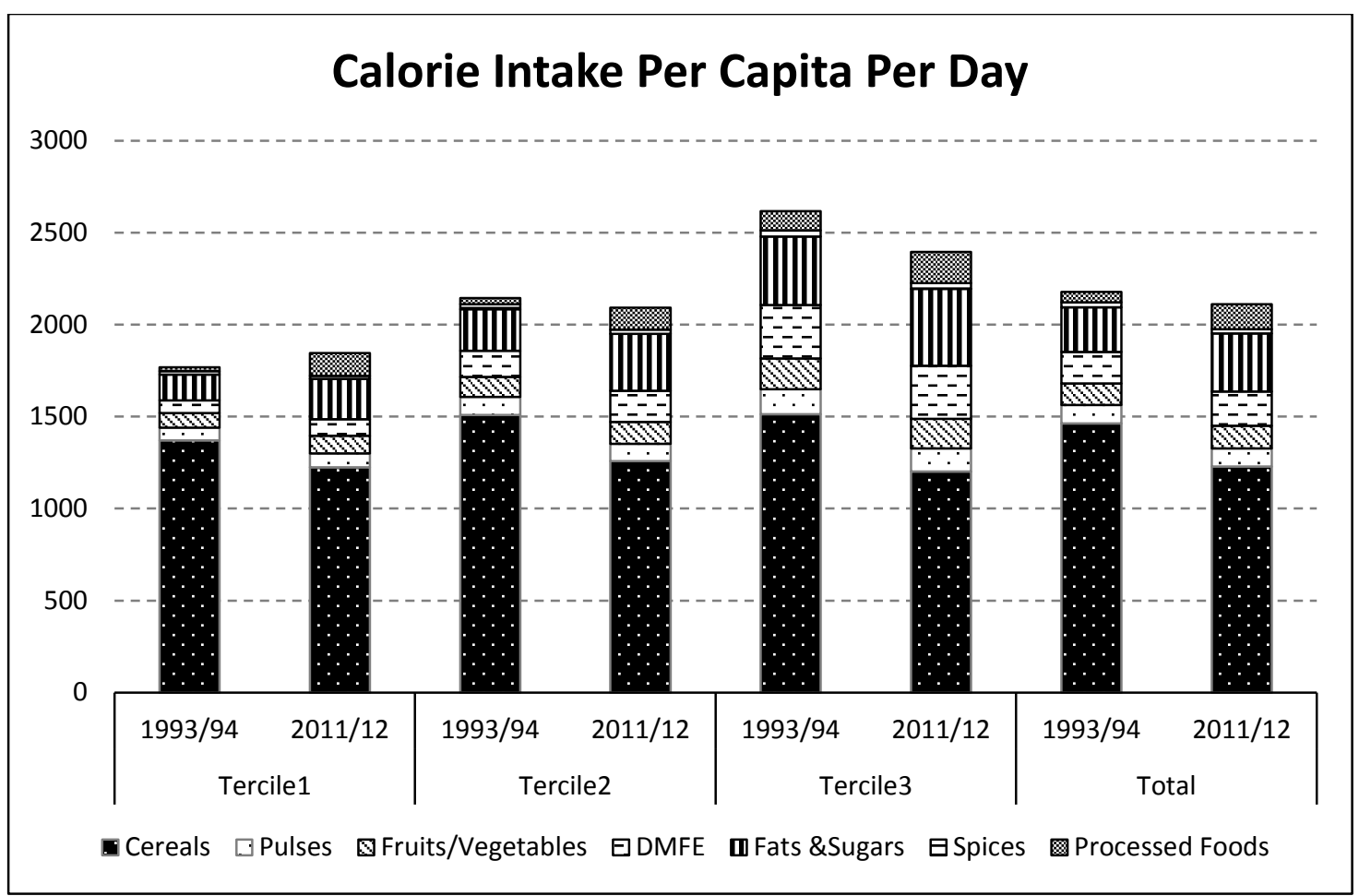




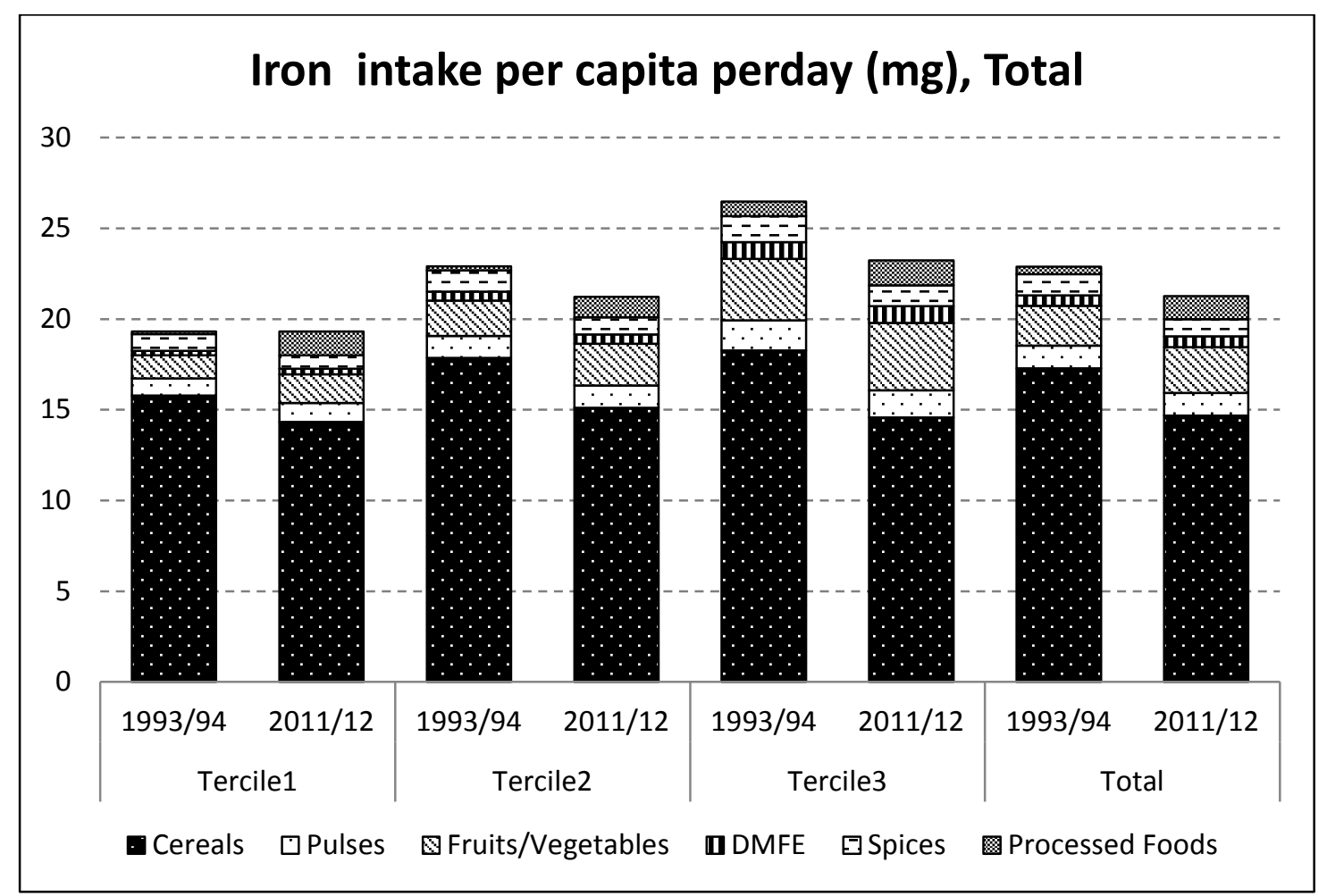

Source: Computed from the unit-record data of the $50^{\text {th }}$ and $68^{\text {th }}$ rounds of the National Sample Survey Organization surveys.

Note: DMFE refers to Dairy, Meats, Fish and Eggs.

When shares of energy intakes accounted for by these food groups are examined instead, the evidence for diet diversification is not so apparent (Figure 8B). First, cereals continue to dominate as the single largest source of energy-accounting for about two-thirds of intakes among the poorest tercile and half of those among the richest tercile. Over time, their share has declined substantially; as might be expected in accordance with Bennett's Law.

However, there has not been a commensurate increase in either the share of fruits and vegetables, or that of livestock products; rather, there has been an increase in the share of energy derived from sugars and oils and other foods.

To put the evidence presented in Figure 8 in perspective, a comparison in absolute terms is instructive. There are, as expected, marked differences across terciles: the richest tercile derive far more calories from non-cereals than do the poorest tercile. However, the poorest tercile saw an increase in the consumption of oils and sugars from 135 to 216 calories pcpd, a far greater increase than the 340 to 390 calories pcpd seen among the richest tercile. The per capita caloric intake from fruits and vegetables increased from 80 to 95 calories pcpd among the poorest tercile, but decreased slightly for the richest tercile from 166 to 160 calories pcpd. Calories from dairy, poultry and meat increased from 68 to 90 calories for the poor and remained unchanged at about 300 calories for the rich. There was virtually no change in the caloric intake from pulses, which remained virtually the same across the two 
years at 75 calories pcpd for the poorest tercile and 125 calories pcpd for the richest tercile. The unchanged consumption of pulses is not surprising, given that per capita net-availability of pulses has remained the same over this period, with nearly 4 million tons of imports needed to achieve this. For vegetarian diets, however, this implies that protein intakes are not increasing.

This pattern of diet diversification is found in rural areas as well; with lower consumption of cereals, but only modest increases in calories derived from livestock products and fruits and vegetables. Given the length of the time period being considered, and the disaggregation by income tercile group, these are fairly modest changes in diet composition; one would have expected to see greater changes at least among the richer tercile. There has however also been an expansion in the percentage of households consuming more diverse products. To this limited extent, diet quality appears to correlate well with improvements in nutritional outcomes (except anemia).

A particular concern, given the discussion on overweight and obesity above, is the increase in the consumption of sugars and oils. The NSSO estimates of overall fat intakes suggest an increase from 31 grams pcpd in 1993/94 to 42 grams pcpd in 2011/12 (NSSO, 2014) in rural India and from 42 to 53 grams pcpd in urban India; ${ }^{18}$ these increases are to be seen against the backdrop of an overall decline in energy intakes as reported by the NSSO.

A note on the measurement of nutrient intakes is in order here. The calorie intake figures reported above are likely underestimated, for there are concerns about whether the NSSO adequately captures processed foods or meals consumed outside the home, both of which are likely high in fats, sugars or both (see Tandon and Landes, 2011 and Meenakshi and Viswanathan, 2013). The NSSO surveys record a consistent increase in the number of meals taken outside the home (other than school meals); these are not accounted for in the estimated energy intakes. Given this, the degree of underestimation in energy intakes is probably increasing over time. Although it is not possible to ascertain the calorie and nutrient content of meals consumed outside the home, Meenakshi and Viswanathan (2013), using conservative assumptions on the energy content of meals outside the home (based on the work of Tandon and Landes, 2011), note that this fact alone can account for almost the entire decrease in average energy intakes in rural India between 1993/94 and 2009/10; they show that a simple accounting for meals has a substantial impact on the estimated magnitudes of the prevalence of undernutrition. Furthermore, the underestimation is likely greater among richer income groups, for the relatively affluent eat out more frequently and spend more when they do, than those not so affluent.

Other factors that may have resulted in a systematic and time-varying bias in estimated intakes include changes in the number of commodities canvassed and recall period. The NSSO has traditionally used as 30-day recall period. Several years ago, the NSSO conducted a pilot survey to compare consumption estimates from 7-day and 30-day recalls against the gold standard of a 24-hour recall. Their results suggested that while the estimates did not vary for cereals, a shorter recall period mattered more for the non-cereals. This suggests that as diets have diversified away from cereals, the underestimation of intakes from other foods is becoming more salient over time (for more details see Meenakshi and Viswanathan,

${ }^{18}$ One gram of fat contains approximately 9 calories; Figure $8 \mathrm{~B}$ is in caloric terms. 
2013). Similarly, there has been a trend towards reduction in the number of food items canvassed, which also may have resulted in increasingly under-estimated intakes.

Despite these caveats, the magnitudes of average caloric intakes derived from fats (and sugars) presented in Figure 8 do not seem high relative to requirements. The National Nutrition Monitoring Bureau (NNMB) uses more accurate dietary assessment methods to compute food intakes, and has followed about 90 villages since the mid-1970s. ${ }^{19}$ These surveys (NNMB, 2012) also show an increase in the consumption of fats and oils over time in rural India, but note that the averages are still below recommended dietary intakes. In fact, Dorin (1999) voiced concerns over a deficiency in fats, especially in rural diets. Yet, states that witnessed the highest increases in overweight and obesity are also those that saw the greatest increases in average fat intakes: for example, fat intake in rural Tamil Nadu increased by nearly $60 \%$ (compared the all India average of $28 \%$ ). In addition, there is much greater inequality in fat intakes than in calories, with higher income groups consuming $70 \%$ more fats than the average, but only a third more of calories (NSSO, 2014). This suggests that although average intakes may still be low, consumption inequalities in fats and oils (perhaps exacerbated when measurement issues are factored in), may be one driver of the increase in obesity levels. Another explanation for the rising obesity levels is the decline in physical activity levels, not just in urban areas, but rural areas as well, but there is little evidence on this (see Eli and Li, 2015).

In addition to energy and budget shares, Figure $8 \mathrm{C}$ presents comparisons for one micronutrient, iron, over the same time period, with intakes computed using nutrient conversion factors provided by Gopalan et al. (2011). The inadequacy of micronutrients in the Indian diet has not received as much attention in the literature, although the problem was flagged as early as the 1980s (see Dasgupta, 1983, for example). Aggregate iron intakes have decreased over time, but only for the top two tercile expenditure groups. Cereals constitute the major source of dietary iron, not because they are rich in iron, but because they are consumed in large quantities. And the decreases are largely a reflection of lower cereal consumption, which are larger in magnitude than the modest increases seen in iron intakes from meat, eggs and fish (see Sharma, 2015 for further details). These figures have been calculated using existing conversion factors; the estimated iron content of various foods have been revised downwards substantially by the National Institute of Nutrition but the new conversion factors are not yet in the public domain. Thus, actual intakes are likely at least a third lower than what is presented in the figure. A decrease in iron intakes over time is reported also by the NNMB (2012): their figures suggest that iron intakes of adult women (and men) declined significantly between the mid-1970s and 2011/12 in rural India.

These trends in diet quality are consistent with movements in relative prices. Over the last decade, India has witnessed among the highest rates of food-price inflation among emerging economies, with food inflation exceeding non-food inflation by 3.5 percentage points between 2006/7 and 2013/4 (Anand, et al., 2016). The single largest contributor to food inflation was milk prices, followed by eggs meat and fish, and then cereals (Bhattacharya and Sen Gupta, 2015).

\footnotetext{
${ }^{19}$ Although not a true panel, 90 of the 120 villages originally sampled are revisited, and a new set of 30 villages are added in every round.
} 
Since increased food prices have a greater impact on consumption patterns on the poor (who spend more of their incomes on food), Figure 9 presents trends in relative prices (with respect to cereals) disaggregated by tercile expenditure group. These are derived using median unit values (calculated by dividing expenditures on a food group by the energy (calories) derived from that food group). Because unit values also capture quality differences, these are, strictly speaking, not prices, but the comparison by tercile group accounts at least in part for quality differences. A comparison based on wholesale price indexes yields similar patterns. Relative to cereals, it is apparent that there has been no increase in the price of oils and sugars. Note also that sugar is made available through the public distribution system at subsidized prices; some states (such as Tamil Nadu and Andhra Pradesh) also provide edible oils through this route; one reason to favor these commodities over milk or vegetables is that they are not as perishable and therefore lend themselves more easily to bulk handling. In Tamil Nadu, in the aggregate, over three-quarters of sugar consumed in rural areas, and two-thirds in urban areas, is sourced from the public distribution system (NSSO, 2013); suggesting that for many (if not most) consumers, the subsidy on these commodities is not infra-marginal.

Gaiha et al. (2014) note that the expenditure elasticity of demand for fats, at 0.86 , is far higher than for calories and that the price elasticity (with respect to an edible oil) is relatively inelastic (in 2004/5) in both rural and urban areas. These magnitudes are changing over time, with responses to prices becoming more inelastic. Estimates of income elasticities of energy derived from fats for 2011/12 are somewhat lower, and price elasticities higher; nevertheless, the implication is that income is likely to be the major driver of the consumption of fats; even if relative prices of oils and sugars had increased, consumption may still have increased.

In contrast, the prices of fruits, vegetables and pulses and of dairy, meat and eggs, have increased relative to the price of cereals across all income groups. But relative price changes appear greater for the poor, with the poorest tercile seeing an increase of nearly 50 percent between 1993/94 and 2011/12, and the richest tercile seeing them increase by approximately 20 percent. Anand et al. (2016) report expenditure elasticities (with respect to food expenditures) equaling or exceeding unity for these food groups, and own-price elasticities that range between -0.56 (for eggs, fish and meat) and -0.88 (for milk and milk products); elasticities reported by Gaiha et al. (2014) are somewhat lower. These changes in relative food prices therefore go some way in explaining the relatively modest changes in diet quality shown in Figure 8.

\section{Cross-sectional associations between dietary quality and malnutrition}

The discussion thus far has focused on changes over time, but the analysis used state-level trends. A more disaggregated analysis, using district-level data is attempted in Figures 10 to 13 , but is based on a single time point (the early 2010s), as for many of the indicators, data for earlier years are not available at the district level. The figure uses information for 512 districts, which were home to nearly $90 \%$ of the Indian population in 2011 . All regressions are estimated non-parametrically, weighted by population shares and the graphs represent bivariate relationships only. Needless to add, these graphs serve to illustrate the potential role of diet quality in mitigating over- and under-nutrition; diet 
Figure 9: Trends in prices of foods (relative to cereals), by tercile income group, 1993/94 to 2011/12

A: Poorest Expenditure Tercile

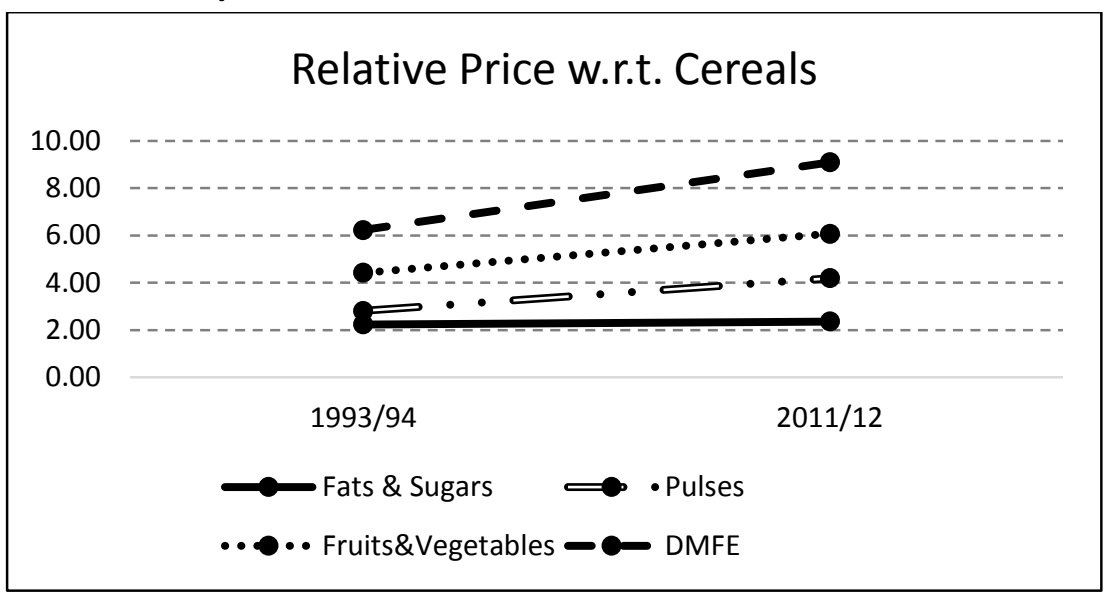

B: Middle Expenditure Tercile

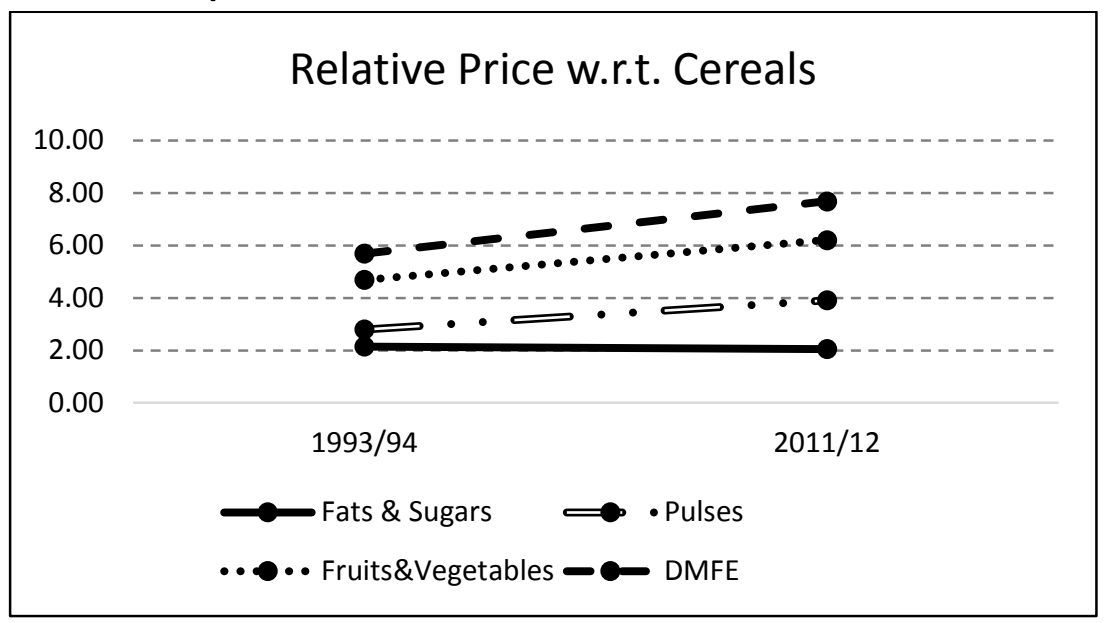

C: Richest Expenditure Tercile

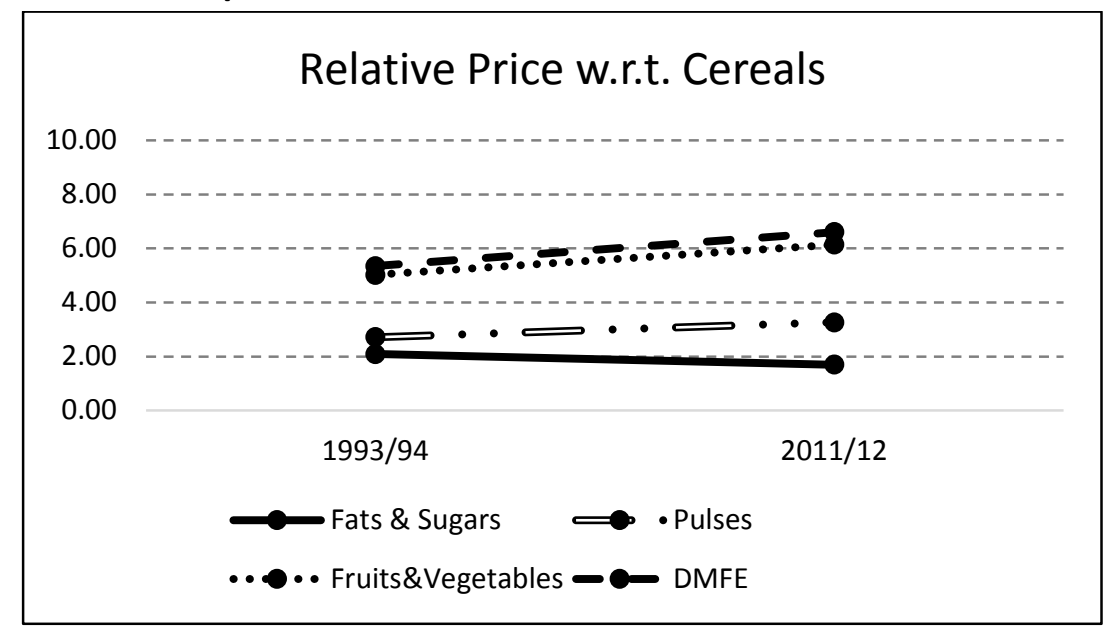

Source: Computed from the unit-record data of the $50^{\text {th }}$ and $68^{\text {th }}$ rounds of the National Sample Survey Organization surveys. 
quality is but one of a complex set of factors that affect malnutrition, but one that has typically not received as much attention in the literature thus far.

Instead of using the share of calories from non-cereal foods as a measure of diet quality, these figures focus on the share from specific food groups such as dairy, meat, eggs and fish; fruits, vegetables and pulses; and oils and sugars. ${ }^{20}$ As indicated in Figure 10, there is a negative relationship between the share of calories obtained from fruits, vegetables and pulses and the two measures of undernutrition (the prevalence of thin women and stunting among children). Both measures decline significantly with this measure of diet quality, but there is a wide spread in the scatter. These negative associations also hold when the diet quality measure is the share of energy derived from dairy, meat, eggs and fish (Figure 11) but the slopes are much flatter and insignificantly different from zero for stunting. ${ }^{21}$ Similarly the prevalence of anemia among adult women decreases with the share of energy derived from each of the two food groups (graphs not presented for reasons of space). ${ }^{22}$

Turning to overweight and related health issues in Figure 12, as expected, there is a positive correlation between the share of energy derived from oils and sugars and measures of overnutrition. It would appear that indicators of overnutrition are far more responsive to worsening diet quality (increased shares of oils and fats) than indicators of undernutrition are to improving diet quality reflected in Figures 10 and 11 . There also appears to be a greater slope (in absolute terms) in the relationship between overnutrition and consumer expenditure, than between undernutrition and consumer expenditure (in Figure 13).

At the same time there are also positive relationships between measures of overnutrition and the other measures of diet quality: the meat, egg and fish or the pulses, fruits and vegetable shares in total energy (figures not presented for reasons of space). While a greater reliance on (red) meats is associated with obesity in developed countries, it is surprising to see this in India as well. This apparently perverse result can be explained by an income effect that underlies both variables: richer districts have greater levels of obesity and better diet quality.

\section{Summary and Implications}

Taken together, this evidence highlights the rapid emergence of overnutrition as a public health problem. Overweight and obesity are no longer confined to the urban domain but appear widespread in rural areas as well. Non-communicable diseases associated with overnutrition and obesity are also increasingly important, and are occurring at far lower levels of fat intake and overnutrition than is the case in most developed countries. At the same time, the magnitudes of most indicators of undernutrition remain high, despite progress.

\footnotetext{
${ }^{20}$ As was the case with state-level trends, there are no significant cross-sectional relationships between measures of undernutrition and levels of energy intakes.

${ }^{21}$ When districts in the state of Uttar Pradesh are dropped the expected negative relationship between stunting and the share of energy from dairy and meats is seen, but the slope is small; this is in contrary to the global evidence of stunting being highly responsive to the consumption of animal-source foods.

22 In a companion paper, district level data are used in a multiple regression framework to assess which, among the many factors, undernutrition appears most sensitive to.
} 
Figure 10. Associations (district-level) between measures of undernutrition (percent of thin women; percent of stunted children) and share of energy derived from fruits, vegetables and pulses, 2011-14

A: Percentage of Women with BMI $<18.5$ and Energy Share of Fruits Vegetables and Pulses

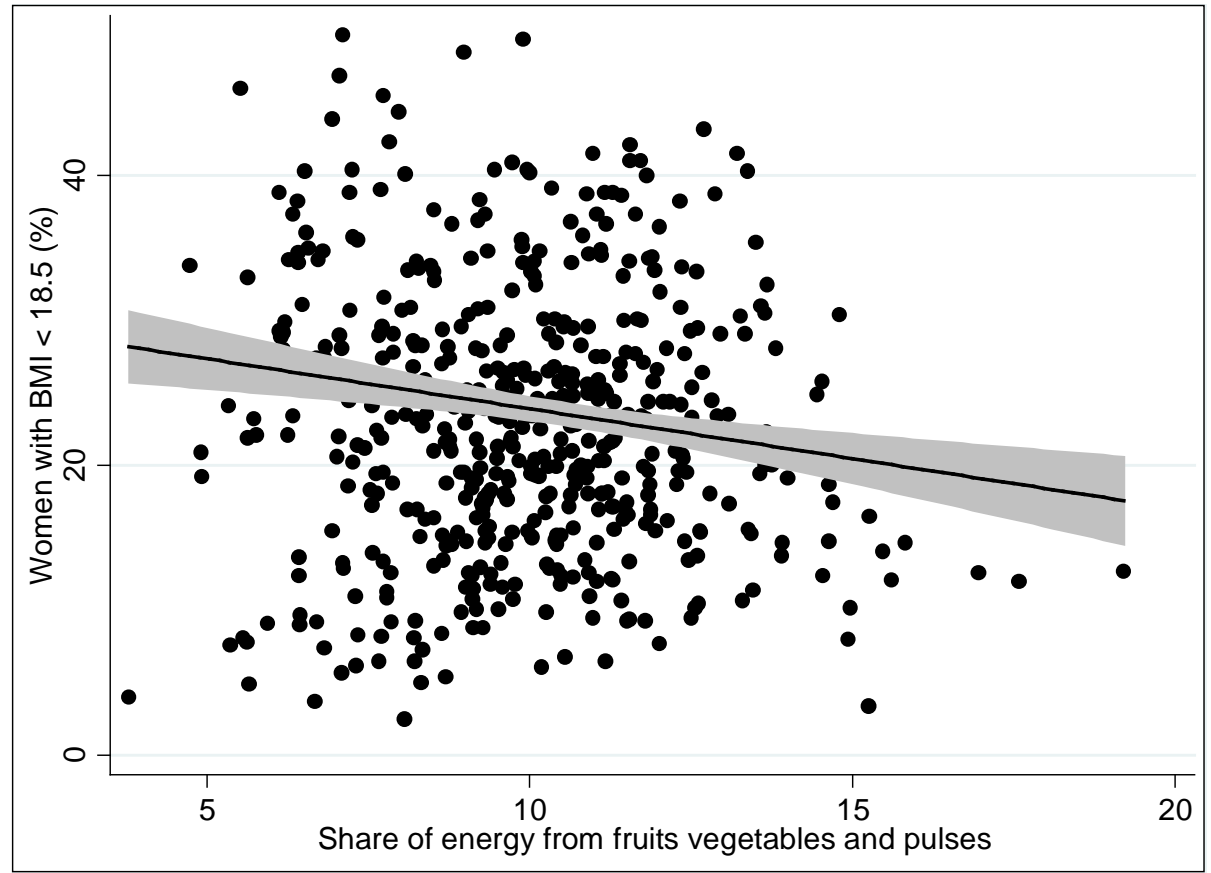

B: Percentage of Stunted Children and Energy Share of Fruits Vegetables and Pulses

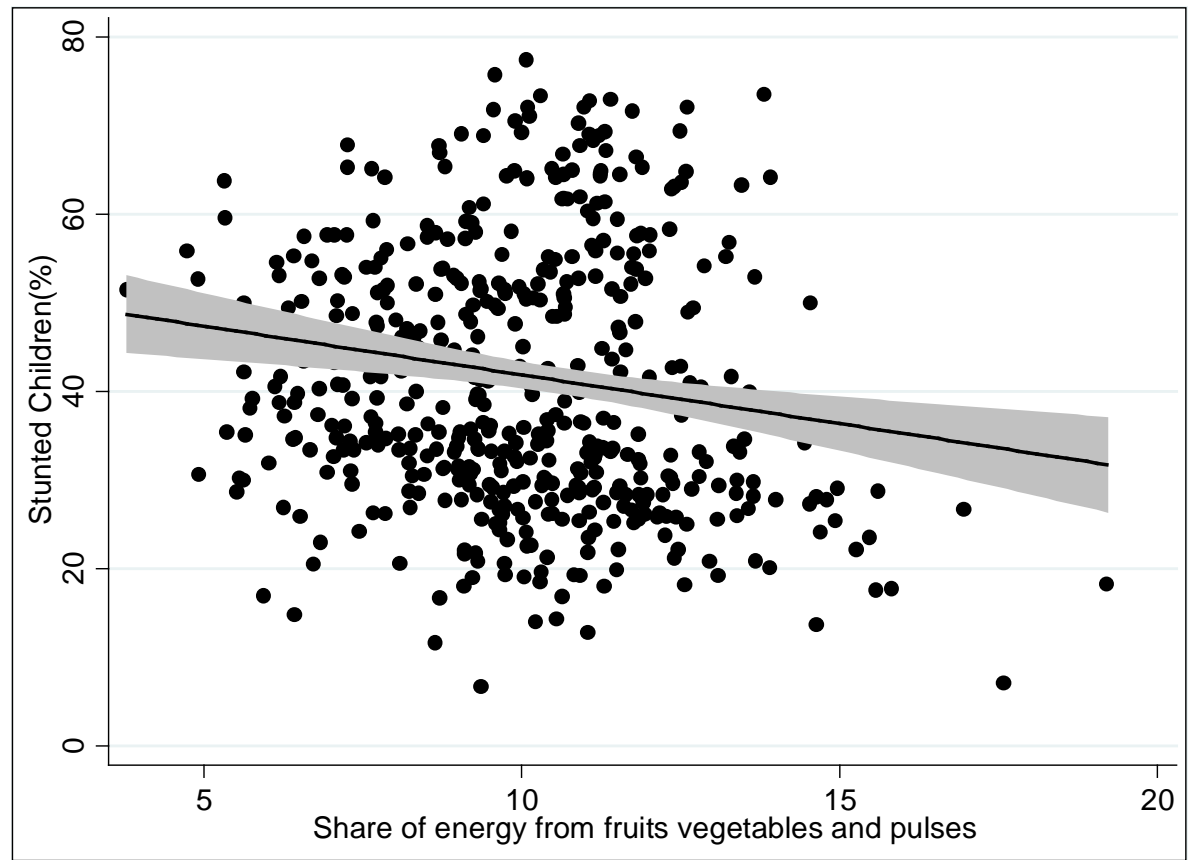

Sources: Share of energy from fruits, vegetables and pulses derived from unit-record data of the $68^{\text {th }}$ round of National Sample Survey Organization surveys (2011/12). Measures of undernutrition taken from the fourth District Level Household and Facility Survey and the Annual Health Survey (2012/13 or 2014). 
Figure 11. Associations (district-level) between measures of undernutrition (percent of thin women; percent of stunted children) and share of energy derived from Dairy, Meat, Eggs and Fish, 2011-14

A: Percentage of Women with BMI $<18.5$ and Energy Share of Dairy Meat Eggs \& Fish

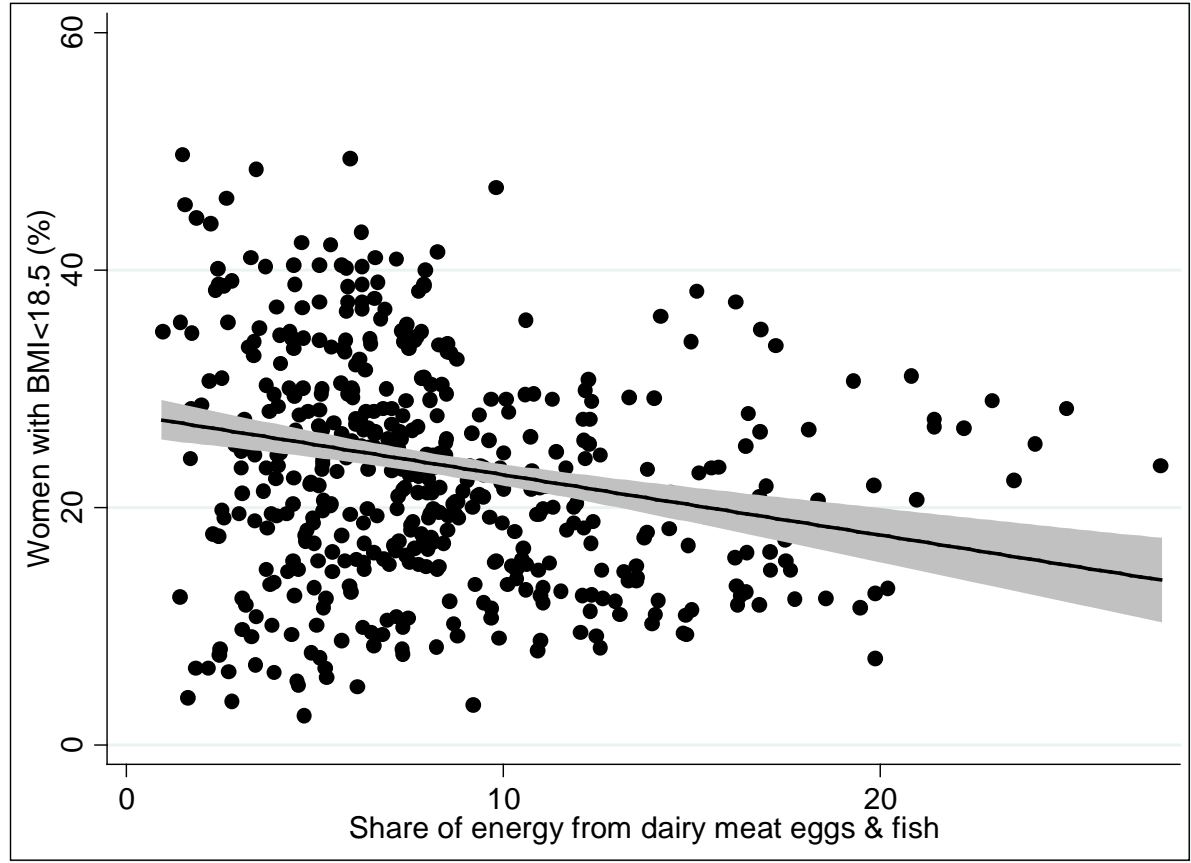

B: Percentage of Stunted Children and Energy Share of Dairy Meat Eggs \& Fish

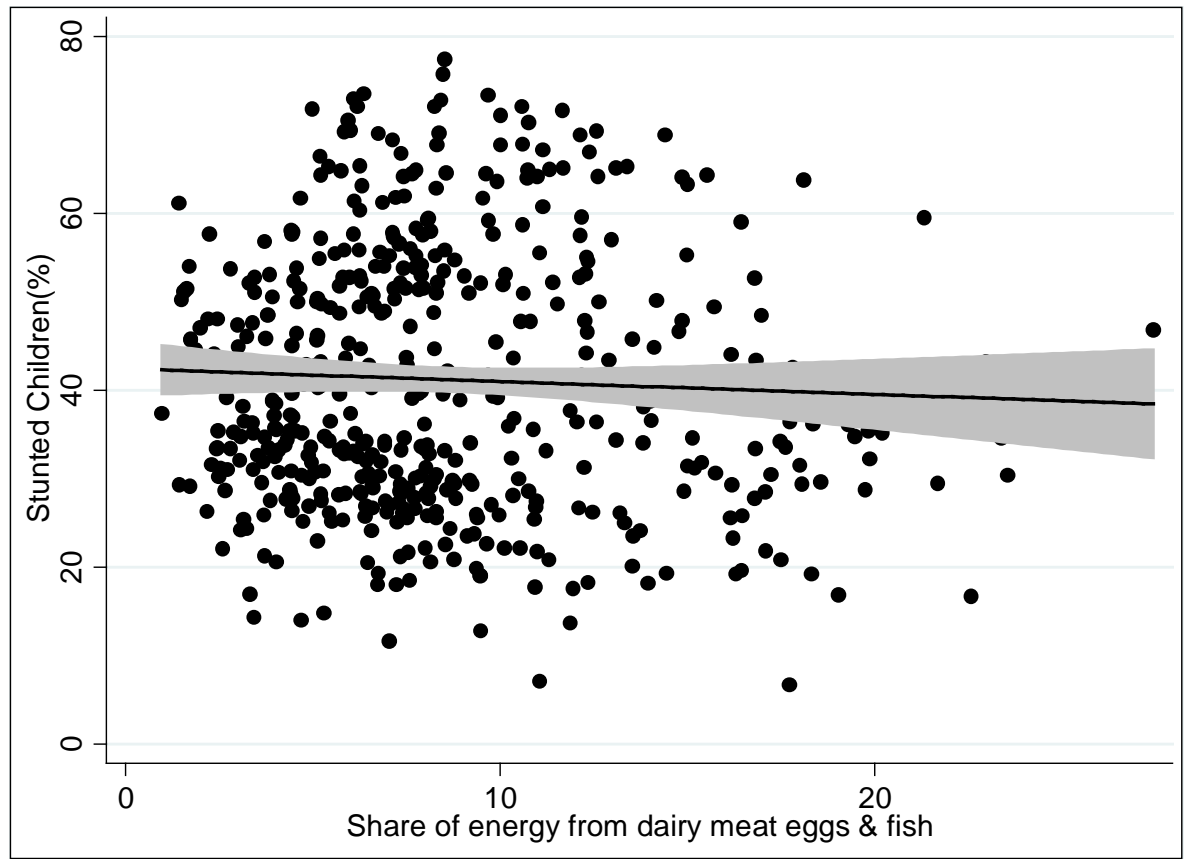

Sources: Share of energy from dairy meat eggs and fish derived from unit-record data of the $68^{\text {th }}$ round of National Sample Survey Organization surveys (2011/12). Measures of undernutrition taken from the fourth District Level Household and Facility Survey and the Annual Health Survey (2012/13 or 2014). 
Figure 12. Associations (district-level) between measures of overnutrition (percent of overweight/obese women; percent of women with diabetes) and share of energy derived from oils and sugars, 2011-14

A: Percentage of Women with BMI > 25 and Energy Share of Oils \& Sugars

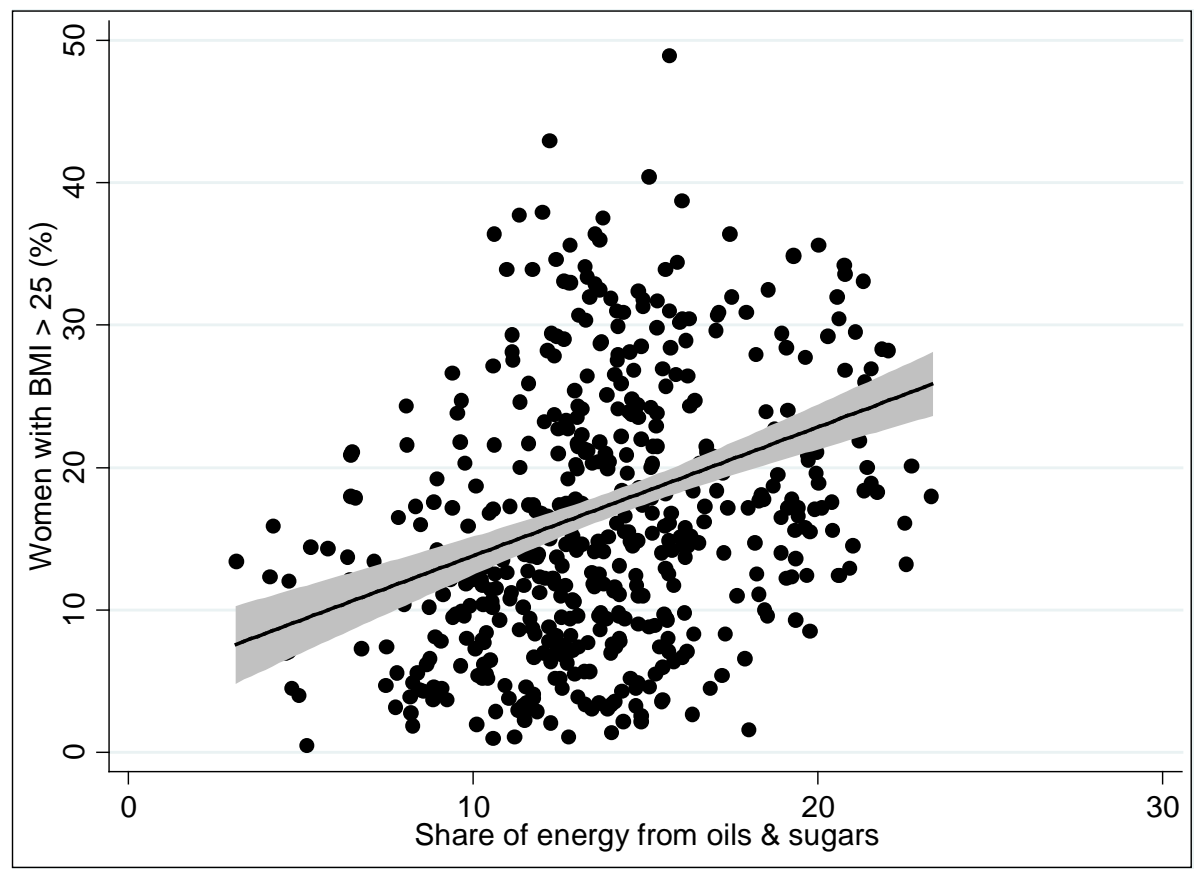

B: Percentage of Women with Diabetes and Energy Share of Oils \& Sugars

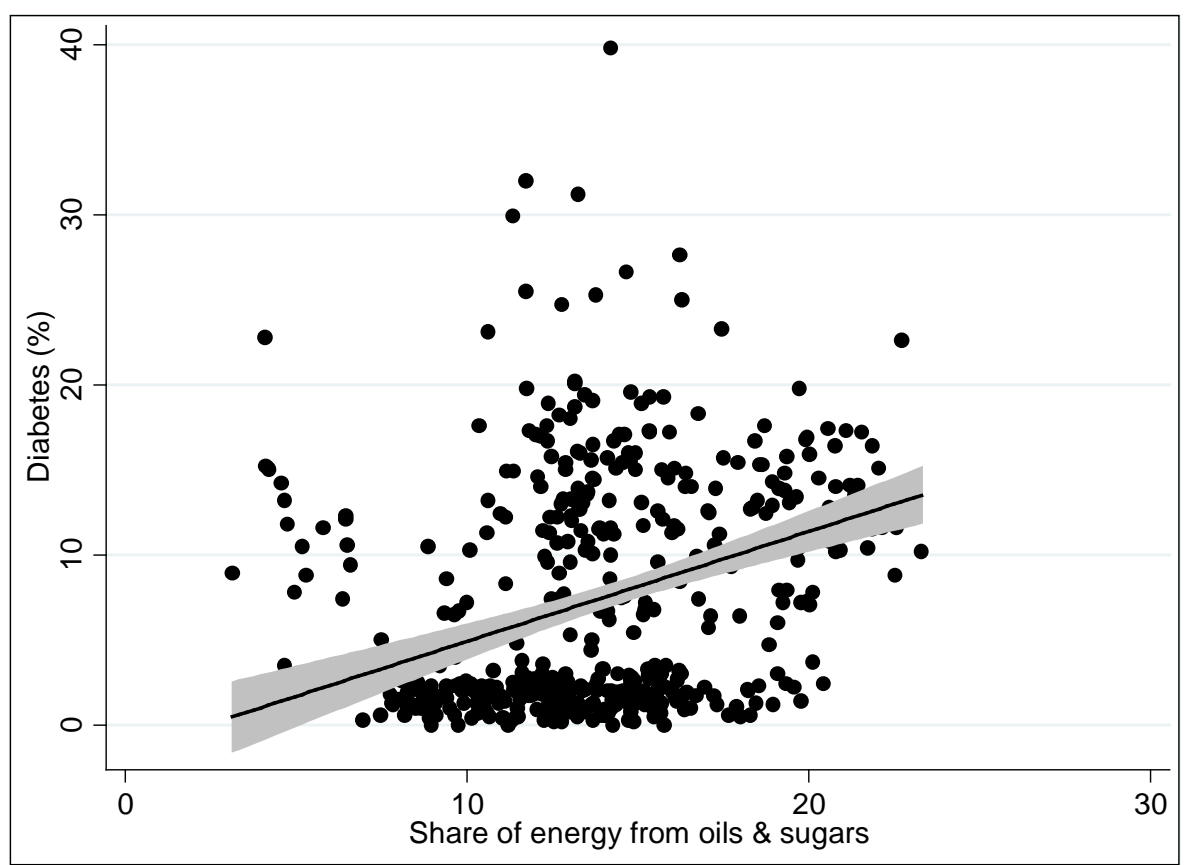

Sources: Share of energy from fruits, vegetables and pulses derived from unit-record data of the $68^{\text {th }}$ round of National Sample Survey Organization surveys (2011/12). Measures of overnutrition taken from the fourth District Level Household and Facility Survey and the Annual Health Survey (2012/13 or 2014). 
Figure 13. Associations (district-level) between measures of overnutrition and undernutrition with respect to consumption expenditure, 2011-14

\section{A: Percentage of Women with $\mathrm{BMI}>25$ and Consumption Expenditure}

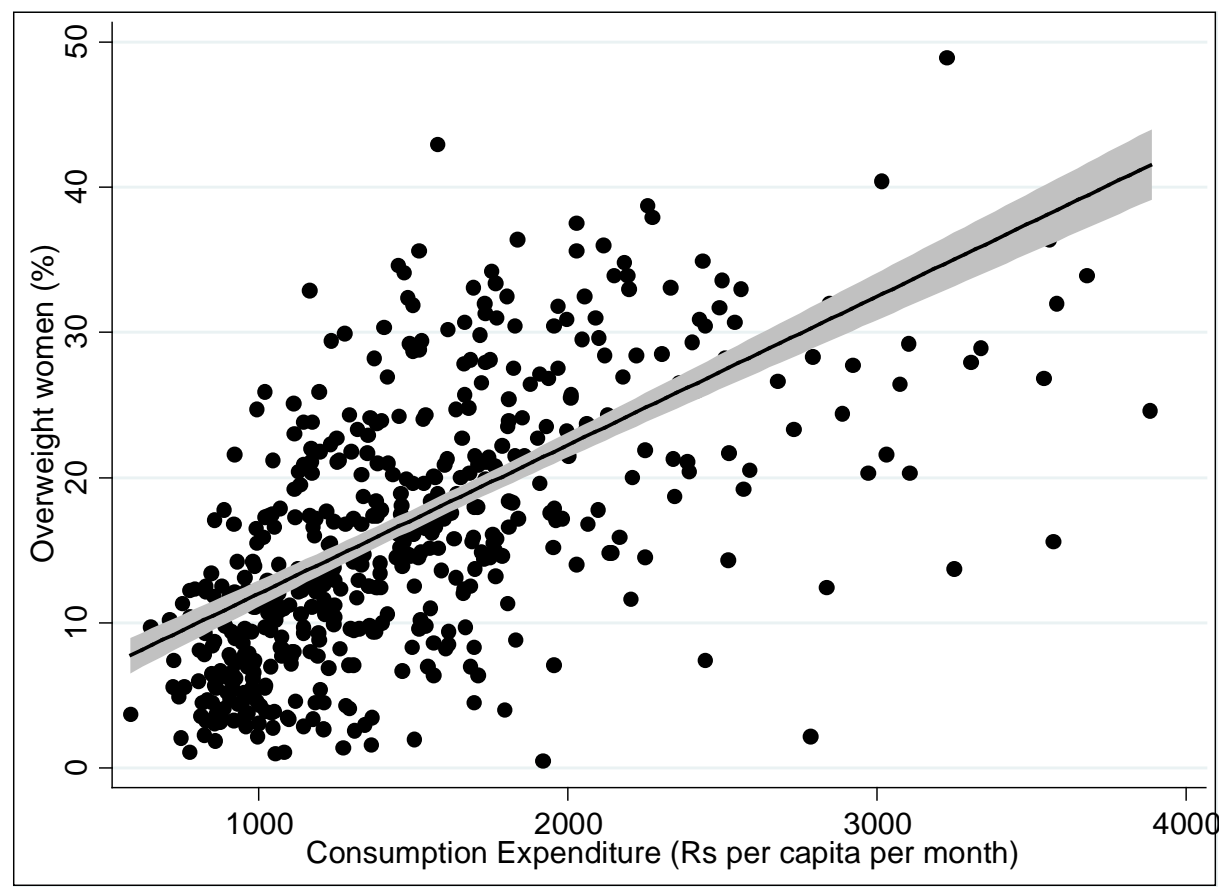

B: Percentage of Women with $\mathrm{BMI}<18.5$ and Consumption Expenditure

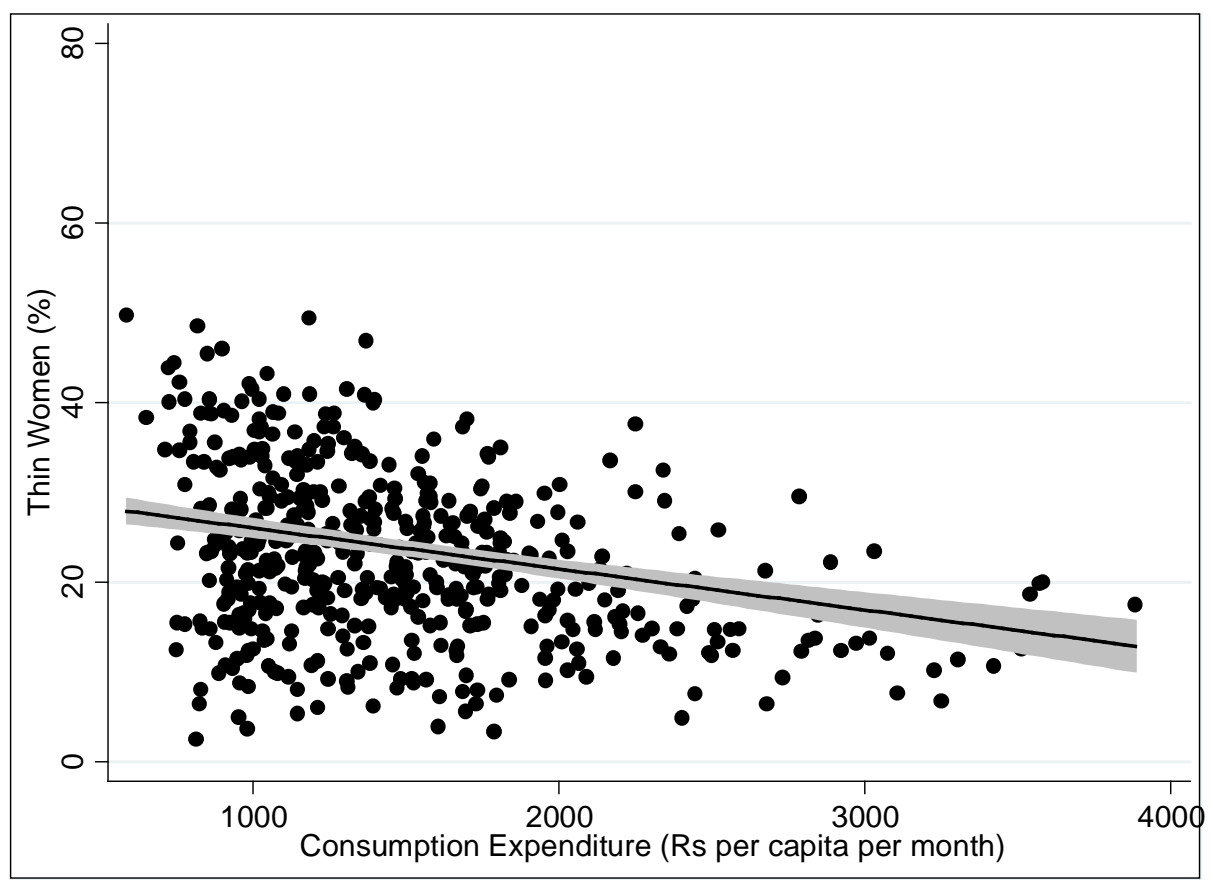

Sources: Consumption Expenditure derived from unit-record data of the $68^{\text {th }}$ round of National Sample Survey Organization surveys (2011/12). Measures of overnutrition and undernutrition taken from the fourth District Level Household and Facility Survey and the Annual Health Survey (2012/13 or 2014). 
More than the quantity of food, it is the quality of diet that appears to be a strong correlate of anthropometric indicators of malnutrition, yet improvements in diet quality (apart from a sustained reduction in the reliance on cereals) have not been very high. These relationships are only suggestive, for they are based on correlations, and use multiple sources of data. However, they are corroborated by state-level trends. It is important to reiterate that the causal factors leading to over- and under-nutrition are complex and not necessarily overlapping, and that this paper has only focused on one factor, namely diet quality.

Nevertheless, that overnutrition should have emerged as a public health concern even in rural areas is cause for concern. To what extent this reflects regional differences (within states, and even districts, reflecting inequality in consumption) or instead points to intrahousehold distributional issues is an open question, but one that needs to be addressed to better inform the design of policy interventions. Both overnutrition and diet quality-two of the three burdens of malnutrition-clearly need more research and policy attention. Another concern is anemia, the incidence of is high and may even have increased in some states, but has not yet seen the policy intervention and attention that it deserves.

These findings need to be interpreted in light of food price policy, which continues to be predominantly focused on cereals. Food inflation, driven increasingly by non-cereals, has likely hindered larger improvements in diet quality, especially for the poor; however, given the available evidence on low price elasticities and possibilities of substitution it is not clear to what extent price interventions in markets for edible oils and sugars will be effective in moderating increases in demand. ${ }^{23}$

Regional differences are important, as both levels and changes vary by state, and in ways not always explained by income differentials. Although Kerala has had a history of interventions in the social sector, the experiences of other states also point to the difference that can be effected in a very few years, irrespective of the level of poverty. For example, Tamil Nadu has had better implementation of programs such as the Integrated Child Development Scheme (a pre-school intervention) as well as the Rural Health Mission more generally. Similarly, Chattisgarh has seen substantial expansion in its public food distribution system. Thus public policy, implemented at the state-level, has an important role in effecting better public health outcomes.

In addition to these macro-interventions, more nuanced public health interventions are also needed. Many of the states that are witnessing the most rapid increases in the triple burden of malnutrition are also the states with better public health infrastructure. But they need to be refocused to tackle both under- and over-nutrition.

\footnotetext{
${ }^{23}$ The National Food Security Act, for example, does open up a move to cash transfers in lieu of the subsidized price regime currently in place (primarily for cereals, but also for other sugars and fats in states such as Tamil Nadu). Unfortunately, there is very little empirical evidence on cash transfers in India. One study, by Gangopadhyay et al. (2015), randomized on a self-selected sample of consumers in one locality in Delhi suggested that there was no evidence that energy intakes would decline as a consequence of a move to cash, and mild support for an increase in relative expenditures on noncereal foods, but a disaggregation of whether these were spent on 'goods' such as fruits and vegetables or 'bads' such as sugar is not available.
} 


\section{References}

Ackerson, Leland K., Ichiro Kawachi, Elizabeth M. Barbeau, and S.V. Subramanian (2008), "Geography of Underweight and Overweight among Women in India: A Multilevel Analysis of 3204 Neighbourhoods in 26 States" Economics and Human Biology, 6, pp. 264-280.

Anand, Rahul, Naresh Kumar and Volodymyr Tulin (2016), “Understanding India's Food Inflation: The Role of Demand and Supply Factors" International Monetary Fund Working Paper WP/16/2.

Atkin, David (2013), "Trade, Tastes and Nutrition in India" American Economic Review, 103(5), pp. 1629-1663.

Basole, Amit and Deepankar Basu (2015), "Fuelling Calorie Intake Decline: Household-level Evidence from Rural India" World Development, pp. 82-95.

Bennett, Merrill K. (1941), "International Contrasts in Food Consumption" Geographical Review, 31(3), pp. 365-76.

Bhattacharya, Rudrani and Abhijit Sen Gupta (2015), "Food Inflation in India: Causes and Consequences" National Institute for Public Finance and Policy Working Paper 2015-151, New Delhi.

Dasgupta, Rajaram (1983), "Estimation of Nutritional Intakes" Economic and Political Weekly, 18(28).

Deaton, Angus and Jean Dreze (2009), "Food and Nutrition in India: Facts and Interpretations" Economic and Political Weekly, 44(7), pp. 42-65.

Dorin, Bruno (1999), "Food Policy and Nutritional Security: Unequal Access to Lipids in India" Economic and Political Weekly, 34(26).

Eli, Shari and Nicholas Li (2015), "Caloric Requirements and Food Consumption Patterns of the Poor" NBER Working Paper 21697

FAO (2006), "The Double Burden of Malnutrition: Case Studies from Six Developing Countries" FAO Food and Nutrition Paper 84.

Gaiha, Raghav, Raghbendra Jha and Vani S. Kulkarni (2014), "Demand for Nutrients in India, 1993-2004" Chapter 2 in Raghav Gaiha, Raghbendra Jha and Vani S. Kulkarni, Diets, Malnutrition and Disease: The Indian Experience, Oxford University Press.

Gaiha, Raghav, Raghbendra Jha and Vani S. Kulkarni (2014), “How Pervasive is Eating Out in India" Chapter 4 in Raghav Gaiha, Raghbendra Jha and Vani S. Kulkarni, Diets, Malnutrition and Disease: The Indian Experience, Oxford University Press.

Gangopadhyay, Subhashis, Robert Lensink and Bhupesh Yadav (2015), "Cash or In-Kind Transfers? Evidence from a Randomised Control Trial in Delhi, India" Journal of Development Studies 51(6). 
Gopalan, C, B.V. Rama Sastri, and S.C. Balasubramanian, with B.S. Narasinga Rao, Y.G. Deosthala and K.C. Pant (2011), Nutritive Value of Indian Foods, National Institute of Nutrition, Indian Council of Medical Research.

Kaicker, Nidhi, Vani S. Kulkarni and Raghav Gaiha (2014), "Dietary Transition in India: An Analysis based on NSS Data, 1993-2004" Chapter 3 in Raghav Gaiha, Raghbendra Jha and Vani S. Kulkarni, Diets, Malnutrition and Disease: The Indian Experience, Oxford University Press.

Masters, William, Anaya Hall, Elena Martinez, Peilin Shi, Gitanjali Singh, and Dariush Mozaffarian (2016), "The Nutrition Transition and Agricultural Transformation: A Preston Curve Approach" Agricultural Economics, this volume.

Meenakshi, J.V. and Brinda Viswanathan (2013), "Estimation of Calorie Norms and Measurement of Food Intakes: Some Implications for the Magnitudes of the Prevalence of Undernutrition in India" Indian Economic Review, XLVIII (1), pp. 167-188.

National Nutrition Monitoring Bureau (2012), Diet and Nutritional Status of Rural Population, Prevalence of Hypertension and Diabetes among Adults and Infant and Young Child Feeding Practices: Report of Third Repeat Survey, Technical Report number 26, National Institute of Nutrition, Indian Council of Medical Research, Hyderabad

National Sample Survey Organization (2014), Nutritional Intake in India, 2011-12, NSS 68 ${ }^{\text {th }}$ Round, Ministry of Statistics and Programme Implementation, Government of India

National Sample Survey Organization (2013), Public Distribution and Other Sources of Household Consumption, NSS $66^{\text {th }}$ Round, Ministry of Statistics and Programme Implementation, Government of India

Panagariya, Arvind (2013), "Does India Really Suffer from Worse Child Malnutrition than Sub-Saharan Africa?" Economic and Political Weekly, XLVIII (18).

Pinstrup-Andersen (2007), "Agricultural Research and Policy for Better Health and Nutrition in Developing Countries: A Food Systems Approach" Agricultural Economics, 37(S1), pp.187198.

Ramachandran, Prema (2011), "The Nutrition Transition in India" NFI Bulletin, 32(2)

Ramachandran, Prema (2014), "Triple Burden of Malnutrition in India: Challenges and Opportunities," Chapter 2 in IDFC Foundation, India Infrastructure Report 2013/14: The Road to Universal Health Coverage, Orient Blackswan.

Ramachandran, Prema (2006), "The Double Burden of Malnutrition in India," in FAO (2006), op. cit.

Sharma, Rekha (2015), Quantifying Undernutrition in Rural India, Academic Foundation.

Stein, Alexander, J.V. Meenakshi, Matin Qaim, Penelope Nestel, H.P.S. Sachdev and Zulfiqar A. Bhutta (2008), "Potential Impacts of Iron Biofortification in India" Social Science and Medicine, 66, 1797-1808. 
Tandon, Sharad and Maurice Landes (2011), "The Sensitivity of Food Security in India to Alternate Estimation Methods: An Analysis" Economic and Political Weekly, 46, pp. 92-99.

Vaz, M., S. Yusuf, A.V. Bharathi, A.V. Kurpad, and S. Swaminathan (2005), "The Nutrition Transition in India" South African Journal of Clinical Nutrition, 18(2).

WHO Multicentre Growth Reference Study Group (2006), WHO Child Growth Standards: Length/height-for-age, weight-for-age, weight-for-length, weight-for-height and body mass index-for-age: Methods and development, Geneva.

http://www.who.int/childgrowth/standards/technical_report/en/

\section{Appendix A: Legends for Abbreviated State Names Used in the Figures}

$\begin{array}{ll}\text { CHA } & \text { Chattisgarh } \\ \text { JHA } & \text { Jharkhand } \\ \text { BIH } & \text { Bihar } \\ \text { ODI } & \text { Odisha } \\ \text { ASS } & \text { Assam } \\ \text { MP } & \text { Madhya Pradesh } \\ \text { UP } & \text { Uttar Pradesh } \\ \text { HAR } & \text { Haryana } \\ \text { KAR } & \text { Karnataka } \\ \text { WB } & \text { West Bengal } \\ \text { MAH } & \text { Maharashtra } \\ \text { GUJ } & \text { Gujarat } \\ \text { RAJ } & \text { Rajasthan } \\ \text { TN } & \text { Tamil Nadu } \\ \text { UTT } & \text { Uttarakhand } \\ \text { AP* } & \text { Andhra Pradesh } \\ \text { PUN } & \text { Punjab } \\ H P & \text { Himachal Pradesh } \\ \text { KER } & \text { Kerala }\end{array}$

*includes Telangana

States in italic typeface were included in the fourth District Level Household and Facility Survey conducted by the Ministry of Health and Family Welfare; the remaining districts were covered under the Annual Health Survey conducted by the Registrar General and Census Commissioner of India. 
Appendix B: Comparing nutritional indicators across data sources for recent (post 2010)

Table B1: Prevalence of stunting among young children

\begin{tabular}{|l|c|c|c|c|c|c|}
\hline \multicolumn{1}{|c|}{ State } & \multicolumn{2}{|c|}{ Total } & \multicolumn{3}{c|}{ Rural } \\
\hline $\begin{array}{c}\text { DLHS 4 } \\
\text { (2012/13) OR } \\
\text { AHS (2014) }\end{array}$ & $\begin{array}{c}\text { RSOC } \\
\mathbf{( 2 0 1 3 / 1 4 )}\end{array}$ & $\begin{array}{c}\text { NFHS 4 } \\
\mathbf{( 2 0 1 5 / 1 6 )}\end{array}$ & $\begin{array}{c}\text { DLHS 4 } \\
(\mathbf{2 0 1 2 / 1 3 )} \text { OR } \\
\text { AHS (2014) }\end{array}$ & $\begin{array}{c}\text { RSOC } \\
(\mathbf{2 0 1 3 / 1 4 )}\end{array}$ & $\begin{array}{c}\text { NFHS 4 } \\
\mathbf{( 2 0 1 5 / 1 6 )}\end{array}$ \\
\hline Bihar & 52.0 & 49.4 & 48.3 & 52.6 & 49.9 & 49.3 \\
\hline Madhya Pradesh & 51.5 & 41.5 & 42.0 & 49.6 & 44.7 & 43.6 \\
\hline Karnataka & 29.9 & 34.2 & 36.2 & 29.1 & 34.2 & 38.5 \\
\hline West Bengal & 37.4 & 34.7 & 32.5 & 39.7 & 38.6 & 34 \\
\hline Maharashtra & 30.0 & 35.4 & 34.4 & 30.0 & 36.3 & 38.4 \\
\hline Tamil Nadu & 27.3 & 23.3 & 27.1 & 30.1 & 26.0 & 28.6 \\
\hline Uttarakhand & 40.2 & 34.0 & 33.5 & 41.9 & 37.3 & 34 \\
\hline Haryana & 31.9 & 36.5 & 34.0 & 32.1 & 37.6 & 34.3 \\
\hline Andhra Pradesh* & 26.0 & 35.4 & 30.1 & 23.4 & 37.5 & 32.8 \\
\hline *includes Telangana & & & & & & \\
\hline
\end{tabular}

Table B2: Prevalence of underweight among young children

\begin{tabular}{|c|c|c|c|c|c|c|}
\hline \multirow[b]{2}{*}{ State } & \multicolumn{3}{|c|}{ Total } & \multicolumn{3}{|c|}{ Rural } \\
\hline & $\begin{array}{c}\text { DLHS } 4 \\
\text { (2012/13) OR } \\
\text { AHS (2014) }\end{array}$ & $\begin{array}{c}\text { RSOC } \\
(2013 / 14)\end{array}$ & $\begin{array}{c}\text { NFHS } 4 \\
(2015 / 16)\end{array}$ & $\begin{array}{c}\text { DLHS } 4 \\
(2012 / 13) \text { OR } \\
\text { AHS (2014) }\end{array}$ & $\begin{array}{c}\text { RSOC } \\
(2013 / 14)\end{array}$ & $\begin{array}{c}\text { NFHS } 4 \\
(2015 / 16)\end{array}$ \\
\hline Bihar & 40.3 & 37.1 & 43.9 & 40.8 & 37.7 & 44.6 \\
\hline Madhya Pradesh & 40.6 & 36.1 & 42.8 & 39.6 & 39.5 & 45 \\
\hline Karnataka & 29.7 & 28.9 & 35.2 & 29.6 & 30.2 & 37.7 \\
\hline West Bengal & 37.4 & 30 & 31.5 & 41.7 & 32.7 & 33.6 \\
\hline Maharashtra & 38.7 & 25.2 & 36.0 & 39.9 & 25.7 & 40 \\
\hline Tamil Nadu & 32.5 & 23.3 & 23.8 & 35.1 & 25.1 & 25.7 \\
\hline Uttarakhand & 28 & 20.6 & 26.6 & 30.1 & 21.5 & 27.1 \\
\hline Haryana & 36.2 & 22.7 & 29.4 & 38 & 23.6 & 29.9 \\
\hline Andhra Pradesh* & 28.2 & 22.3 & 30.6 & 30.3 & 22.8 & 33.1 \\
\hline *includes Telangana & & & & & & \\
\hline
\end{tabular}

Table B3: Prevalence of anemia among adult women

\begin{tabular}{|l|c|c|c|c|}
\hline \multicolumn{1}{|c|}{ State } & \multicolumn{2}{|c|}{ Total } & \multicolumn{2}{c|}{ Rural } \\
\hline & $\begin{array}{c}\text { DLHS 4 } \\
(\mathbf{2 0 1 2 / 1 3 )} \text { OR } \\
\text { AHS (2014) }\end{array}$ & $\begin{array}{c}\text { NFHS 4 } \\
\mathbf{( 2 0 1 5 / 1 6 )}\end{array}$ & $\begin{array}{c}\text { DLHS 4 } \\
(\mathbf{2 0 1 2 / 1 3 )} \text { OR } \\
\text { AHS (2014) }\end{array}$ & $\begin{array}{c}\text { NFHS 4 } \\
\mathbf{( 2 0 1 5 / 1 6 )}\end{array}$ \\
\hline Bihar & 87.2 & 60.3 & 86.5 & 60.5 \\
\hline Madhya Pradesh & 83.7 & 52.5 & 83.4 & 53.8 \\
\hline Karnataka & 61.9 & 44.8 & 63.0 & 46.2 \\
\hline West Bengal & 76.7 & 62.5 & 77.6 & 64.4 \\
\hline Maharashtra & 64.8 & 48 & 65.5 & 47.8 \\
\hline Tamil Nadu & 49.2 & 55.1 & 50.1 & 56.8 \\
\hline Uttarakhand & 92.9 & 45.2 & 94.0 & 46.2 \\
\hline Haryana & 56.6 & 62.7 & 57.0 & 63.9 \\
\hline Andhra Pradesh* & 69.3 & 58.7 & 70.3 & 60.1 \\
\hline *includes Telangana & & & & \\
\hline
\end{tabular}


Table B4: Prevalence of overweight or obesity (Body Mass Index $>25$ ) among adult women

\begin{tabular}{|l|c|c|c|c|}
\hline \multicolumn{1}{|c|}{ State } & \multicolumn{2}{|c|}{ Total } & \multicolumn{2}{c|}{ Rural } \\
\hline & $\begin{array}{c}\text { DLHS 4 } \\
(\mathbf{2 0 1 2 / 1 3 )} \text { OR } \\
\text { AHS (2014) }\end{array}$ & $\begin{array}{c}\text { NFHS 4 } \\
\mathbf{( 2 0 1 5 / 1 6 )}\end{array}$ & $\begin{array}{c}\text { DLHS 4 } \\
(\mathbf{2 0 1 2 / 1 3 )} \text { OR } \\
\text { AHS (2014) }\end{array}$ & $\begin{array}{c}\text { NFHS 4 } \\
(\mathbf{2 0 1 5 / 1 6 )}\end{array}$ \\
\hline Bihar & 8.0 & 11.7 & 7.7 & 9.7 \\
\hline Madhya Pradesh & 7.5 & 13.6 & 4.8 & 9.1 \\
\hline Karnataka & 21.0 & 23.3 & 13.8 & 16.6 \\
\hline West Bengal & 16.7 & 19.9 & 12.5 & 15.0 \\
\hline Maharashtra & 17.6 & 23.4 & 11.1 & 14.6 \\
\hline Tamil Nadu & 31.2 & 30.9 & 23.9 & 25.4 \\
\hline Uttarakhand & 23.2 & 20.4 & 19.2 & 16.0 \\
\hline Haryana & 19.0 & 21.0 & 15.6 & 18.8 \\
\hline Andhra Pradesh* & 23.1 & 31.2 & 18.1 & 24.5 \\
\hline *includes Telangana & & & & \\
\hline
\end{tabular}

Table B5: Prevalence of thin-ness (Body Mass Index $<18.5$ ) among adult women

\begin{tabular}{|l|c|c|c|c|}
\hline \multicolumn{1}{|c|}{ State } & \multicolumn{2}{|c|}{ Total } & \multicolumn{2}{c|}{ Rural } \\
\hline & $\begin{array}{c}\text { DLHS 4 } \\
(2012 / 13) \text { OR } \\
\text { AHS (2014) }\end{array}$ & $\begin{array}{c}\text { NFHS 4 } \\
(2015 / 16)\end{array}$ & $\begin{array}{c}\text { DLHS 4 } \\
(2012 / 13) \text { OR } \\
\text { AHS (2014) }\end{array}$ & $\begin{array}{c}\text { NFHS 4 } \\
\text { (2015/16) }\end{array}$ \\
\hline Bihar & 19.8 & 30.4 & 20.6 & 31.8 \\
\hline Madhya Pradesh & 27.9 & 28.3 & 24.2 & 31.8 \\
\hline Karnataka & 27.7 & 20.7 & 33.1 & 24.3 \\
\hline West Bengal & 26.7 & 21.3 & 29.9 & 24.6 \\
\hline Maharashtra & 21.2 & 23.5 & 34.2 & 30 \\
\hline Tamil Nadu & 19.2 & 14.6 & 23.2 & 18.5 \\
\hline Uttarakhand & 19.6 & 18.4 & 21 & 20 \\
\hline Haryana & 22.3 & 15.8 & 25.2 & 18.2 \\
\hline Andhra Pradesh* & 23.5 & 19.8 & 26.8 & 23.3 \\
\hline *includes Telangana & & & & \\
\hline
\end{tabular}

Sources: 2012/13 or 2014 data are from the fourth round of the District Level Household and Facility Survey or the Annual Health Survey; 2013/14 data are from the Rapid Survey on Children; 20015/16 data are from the fourth round of National Family Health Survey.

Note: States in italic typeface were included in the fourth District Level Household and Facility Survey conducted by the Ministry of Health and Family Welfare; the remaining districts were covered under the Annual Health Survey conducted by the Registrar General and Census Commissioner of India. 